SWEDISH SCHOOL OF ECONOMICS

AND BUSINESS ADMINISTRATION

THE YRJÖ JAHNSSON' S WORKING PAPER SERIES IN INDUSTRIAL ECONOMICS

\author{
1 \\ Anthony Dukes \& Esther Gal-Or \\ NEGOTIATIONS AND EXCLUSIVITY \\ CONTRACTS FOR ADVERTISING
}


(C) Swedish School of Economics and Business Administration Anthony Dukes \& Esther Gal-Or

Distributor:

\section{Library}

Swedish School of Economics and Business Administration

P.O.Box 479

00101 Helsinki

Finland

Phone: +358-9-43133 376, +358-9-43133265

Fax: +358-9-43133425

E-mail: publ@shh.fi

http://www.shh.fi/link/bib/publications.htm

Helsingin kauppakorkeakoulun HeSE print, Helsingfors 2001

ISBN 951-555-694-5 


\title{
Negotiations and Exclusivity Contracts for Advertising
}

\author{
Anthony Dukes and Esther Gal-Or
}

February 2001

\begin{abstract}
We develop a theoretical model to examine advertising choices by producers in a differentiated product duopoly. The model includes the media (referred to as stations) that sell advertising space to producers and broadcast advertising messages to consumers. Producers and stations enter bilateral negotiations to determine the price of advertising space. We show that more differentiated media stations and improved effectiveness of primetime advertising yield higher levels of advertising and lower profit margins for producers as well as stations. In contrast, more differentiated product markets enhance the profitability of both the media and the product markets. We further examine the impact on advertising choices of stations offering exclusivity contracts. In the presence of exclusivity contracts, producers' incentive to advertise is lower than without such contracts.
\end{abstract}

For additional information, contact Esther Gal-Or, 210 Mervis Hall, Katz Graduate School of Business, University of Pittsburgh, Pittsburgh PA 15260, esther@mail.business.pitt.edu. Esther Gal-Or acknowledges the support of the National Science Foundation under grant SBR-981-9373. Anthony Dukes wishes to acknowledge the support of the Faculty of Arts and Sciences at the University of Pittsburgh through the Andrew Mellon Predoctoral Fellowship. Both authors wish to express their gratitude to three anonymous referees and the associate editor of this journal whose suggestions have improved this paper significantly. Helpful comments by Rabikar Chatterjee and Jeffery Inman as well as the assistance of John Harpur at MARC - USA are also greatly appreciated. 


\section{Negotiations and Exclusivity Contracts for Advertising}

\section{Introduction}

Commercial media are supported largely, if not fully, by revenues generated by selling advertising space. Producers, who wish to reach many potential customers with each advertising message, seek media who air popular broadcasts. Consequently, media with a large audience have negotiating leverage vis-à-vis producers over the contract price for advertising slots. On the other hand, producers with potentially successful products can afford to pay high prices for advertising space since their marginal return to advertising is high. The media, therefore, seek to sell advertising space to these high demand producers.

Our objective in the present paper is to investigate how the characteristics of the media and product markets determine advertising agreements, as negotiated between media stations and producers. We wish to understand, in particular, how the extent of competitiveness in the two markets affect the strength of the negotiating position of the parties and the resulting terms of the advertising contracts agreed among them. One particular type of contract we emphasize is an exclusivity contract, whereby broadcasters agree to air one producer's advertising messages and exclude those of competitors during part of their broadcast schedule. In our model, such exclusivity rights are offered to producers over time slots of programming when broadcasters experience relatively larger viewership or listenership, such as during primetime in television broadcasting.

Selling exclusive advertising rights during primetime network broadcasts has been common for some time. Recently, in addition, large national syndicates of television programs have been able to make exclusive arrangements with advertisers. These national syndicates do so by entering certain barter syndication agreements with local broadcasters (see Webster 1999). In such agreements, the syndicate, the owner of the rights to a particular program, pays the broadcaster in full for the rights to the entire program-length time slot including all advertising space built into the program. The syndicate can thus exercise full control over the entire space; airing advertising messages of a few producers and excluding those of competing producers. Exclusivity contracts occur in Internet advertising as well. For instance, Internet service provider Yahoo! has displayed banner messages for bookseller Amazon.com while agreeing not to sell ad space to other book sellers (Advertising Age, September 28, 1998). 
In the present paper, both the product and the media markets are assumed to be differentiated duopolies, with the degrees of differentiation between the product producers and the media stations determining the extent of competitiveness of their respective markets. Media stations negotiate with producers over the price of advertising space and, upon agreement, broadcast advertising messages at the intensity requested by producers to consumers who participate in the product market. Only informative advertising is considered whereby advertising messages deliver information about product price and characteristics. The messages constitute the only source of information consumers have about the products available in the market. Producers decide on their intensity of advertising on two different time slots of programming: primetime and non-primetime. Advertising on primetime is more effective since consumers are more likely to tune in and become aware of products that are being advertised during this time slot.

Considering the non-exclusive regime first, when stations cannot exclude any producer from either one of the time slots of programming, we conduct a comparative statics analysis to investigate how changes in the parameters affect the characteristics of the equilibrium. We find that the overall effectiveness of advertising of each producer, as measured by the likelihood of reaching the viewers of the stations, increases when the degree of differentiation between broadcasters is larger, when the producer allocates larger resources to primetime advertising, and when such advertising is significantly more effective than non-primetime advertising. The effectiveness of advertising is independent, however, of the degree of differentiation between product producers. Under a certain reasonable restriction on the function that determines the outreach probability of advertising, we find that both producers and media stations may actually be worse off when the overall effectiveness of advertising is enhanced. As a result, the profits of each station may decline when the extent of differentiation between the programs of different stations is larger or when producers transfer resources from non-primetime to primetime advertising. The greater effectiveness of advertising that is implied by such changes yields better informed consumers and intensified price competition between product producers. Since the only source of revenues for stations and producers to share stems from the producer surplus generated in the product market, intensified price competition in this market reduces the surplus available, to the disadvantage of the negotiating parties. 
When each station can offer exclusivity on primetime to one of the producers, the producer who obtains the exclusivity rights is more likely to reach the viewers of the station than the producer who is excluded from primetime. However, both types of producers reduce their level of advertising as compared to when exclusivity agreements are not feasible. When given more control over the amount of information available, via an exclusive contract, a producer faces a reduced threat of customer stealing by competitors. As a result, the producer that is awarded exclusivity chooses lower amounts of informative advertising. Since such a reduction by the competitor reduces the marginal benefit that the excluded producer derives from advertising this producer follows suit by cutting its advertising level as well. Reduced advertising, in turn, yields alleviated product price competition and may enhance the profitability of both media stations and producers.

Most previous models that address producer's advertising choices in oligopoly do not incorporate media stations as strategic decision makers. Instead, advertising technology is determined by an exogenous production function and the price of advertising is ignored in those models. For example, Grossman and Shapiro (1984), Stahl (1994), LeBlanc (1998), and Cirano and Moreaux (1999) all examine oligopolists' choices of informative advertising without explicitly evaluating the interaction between producers and broadcasters. In oligopoly models of persuasive advertising, such as those by Dixit and Norman (1978), Fruchter and Kalish (1997), Piga (1998), Bloch and Manceau (1999), Fruchter (1999), and von der Fehr and Slevik (1999), the role of broadcasters in determining the price of advertising is ignored, once again. However, the industrial structure of the media market plays an integral role in advertising decisions and product market outcomes. This is revealed by the recent mergers in the media industry. These mergers were driven, in part, by the merger's ability to reach consumers and thereby making the merger attractive to advertisers. To be sure, industry specialists, citing the 1999 merger of CBS and Viacom, suggested that the merger's ability to attract advertisers was the key factor in bringing these two companies together (Business Week, September 20, 1999). This suggests that decisions in the media market can impact the price of advertising and, consequently, producers' advertising choices.

Three recent working papers have incorporated the structure of the media market in analyzing producer's advertising decisions (see Dukes (1999), and Nilssen and Sørgard (2000 
A\&B ${ }^{1}$.) Similar to our focus in the present manuscript, all three papers consider stations as strategic decision makers in an oligopolistic media market. In contrast to our approach, however, where advertising agreements are negotiated between media agents and producers, in Dukes advertising prices are set by an auctioneer to equate the demand for advertising messages with the supply of advertising space and in Nilssen and Sørgard, media stations have the market power to dictate the prices of advertising slots. It turns out that in spite of the negotiation-based approach assumed in the present paper, many of our comparative statics results are consistent with those derived in the above-mentioned papers. In particular, both Dukes and Nilssen and Sørgard demonstrate that intensified competition among media stations reduces advertising levels.

Dukes addresses, like we do here, the effect of product market differentiation on profits and prices. He finds that higher degrees of differentiation between producers results in higher profits to stations and producers. Neither one of the above-mentioned working papers considers the distinction between primetime and non-primetime advertising, nor does any of the papers consider exclusivity agreements between stations and producers.

Using a formulation developed in Gal-Or (1999), we model the exchange of advertising space as bilateral negotiations between media stations and producers. Each station-producer pair jointly agrees on a price for advertising messages by engaging in bilateral negotiations over the mutual gain from reaching an agreement. There is a realistic appeal to using the negotiationbased approach we utilize in this paper. Many Internet services sell advertising space on their websites and ad prices are reached through negotiations. For example, Powerize.com, a business and financial information service, displays advertisers' messages on its website while offering a variety of advertising options with regard to the size and location of the advertising banner. The price of an advertising banner is specified in bilateral negotiations between Powerize.com and the different advertisers (personal correspondence with VP of Business Development, Powerize.com).

Bilateral negotiations for advertising price occur also in the television industry. An NBC affiliate in Pittsburgh, for example, uses recent television viewing ratings to construct a quarterly rate card. The rate card specifies an advertising price for each ad spot in the station's broadcast schedule. These prices serve as a starting point in negotiations with advertisers. If the demand

\footnotetext{
${ }^{1}$ We became aware of the last two working papers while revising the present manuscript.
} 
for an ad space during an upcoming program is relatively low, for instance, negotiations can result in a price lower than that specified by the rate card (personal correspondence with Director of Advertising Sales, WPXI).

Our paper is organized as follows. In the next section we describe the assumptions of our model. In section 3 we derive the equilibria under the assumption that exclusivity clauses are not feasible. In section 4, we investigate the implications of stations offering exclusivity rights to producers during their primetime programming slots, and in section 5 we conclude.

\section{The Model}

Assume a differentiated product market consisting of 2 producers and a differentiated media market consisting of 2 media stations. The preferences of the consumers between the product producers are distributed independently of their preferences between media stations. We model the distribution of preferences by using a location model, with the population of the consumers uniformly distributed on a line of unit length and the firms (either product producers or media stations) located at the endpoints of this line. Figure 1 clarifies the location of the producers and stations on the distribution of preferences.

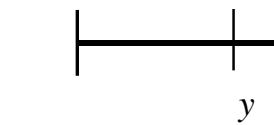

Producer 1

$y$
Product Market

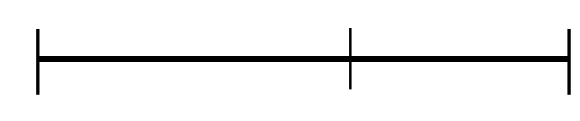

Station 1
Station 2

Figure 1: The Location of Producers and Stations on the Distribution of Preferences

We designate the address of the consumer in the distribution by $y$ and $x$, to identify her preferences between product producers and media stations, respectively. Since preferences between producers are determined independently of preferences between stations, the distances $y$ and $x$ need not coincide for a given consumer.

Each consumer derives the level of utility $v_{p}$ when purchasing a product whose characteristics exactly match her location on the line. Similarly, she derives the level of utility $v_{s}$ when listening to the station whose programming constitutes a best match with her 
preferences. When a consumer buys a product or listens to a station with characteristics different from her "ideal point" on the line her utility declines by $t_{p}$ and $t_{s}$, respectively, per unit of distance. The transportation parameters $t_{p}$ and $t_{s}$ measure the extent of differentiation between product producers and media stations, respectively. Larger values of the transportation parameters reflect increased differentiation and, therefore, less intense competition between the product producers or the media stations. The approach we utilize to characterize the market structures of the media and product markets is the simplest way of introducing competition in each market while still incorporating a market parameter that measures the market's extent of competitiveness. Two participants is the minimal number necessary to introduce competition in each market, and the parameters $t_{p}$ and $t_{s}$ provide a vehicle to vary the extent of competition of the product and media markets, respectively. ${ }^{2}$ Each product producer decides on its level of advertising with each media station. We distinguish between two different time slots of programming by stations: non-primetime $(N P)$ and primetime $(P)$. We designate by $\varphi_{i P}^{j}$ and $\varphi_{i N P}^{j}$ the number of advertising messages producer $i$ chooses to place with station $j$ during primetime and non-primetime, respectively. A given listener of this station will hear at least one of those messages with some probability that depends upon the level of advertising chosen by the producer during the different time slots. We assume that advertising messages aired on primetime are more effective in reaching viewers than messages aired on non-primetime programs. Specifically, each unit of advertising during primetime is $\alpha$ times more effective than during non-primetime programs, where $\alpha \geq 1$. Accordingly, we distinguish between the overall level of advertising that is selected by a producer (i.e. $\varphi_{i N P}^{j}+\varphi_{i P}^{j}$ ) and the effective level of advertising of the producer, which amounts to $\left(\varphi_{i N P}^{j}+\alpha \varphi_{i P}^{j}\right)$. We specify the probability of reaching viewers as a function of the effective units of advertising chosen by the producer. We refer to this probability as the outreach probability. For producer $i$ 's choice of advertising with station $j$ this probability is given by $G\left(\varphi_{i N P}^{j}+\alpha \varphi_{i P}^{j}\right)$, where $G(\cdot) \in[0,1], G(0)=0, G^{\prime}(\cdot)>0$,

\footnotetext{
${ }^{2}$ In an earlier version of this paper two different parameters were utilized to measure the extent of competition in each market: the number of competitors and the extent of differentiation among them. Since the comparative statics with respect to the number of competitors turns out to be qualitatively similar to those with respect to the degree of differentiation among competitors, in the present version we focus only on the degree of differentiation as a measure of the extent of competitiveness of each market.
} 
and $G^{\prime \prime}(\cdot)<0$. Hence the probability of reaching a consumer is increasing at a decreasing rate with the effective level of advertising. Our model considers informative advertising only, where messages inform the listener of the existence of a particular brand, its location on the line (i.e. its characteristics) and its price. Unless a consumer hears an advertising message about at least one of the brands, she remains completely uninformed about this product class and refrains from consumption altogether. Since our objective in this paper is to focus on the relationship between product producers and media stations who air advertising messages on their behalf, we assume that consumers have no other source of information about the products. In particular, search on the part of consumers is assumed to be infinitely expensive. ${ }^{3}$

The utility that a given consumer derives from listening to a certain station depends upon the overall level of advertising messages that this station chooses to put on the air as well as the location of the consumer on the distribution of preferences between the two stations. We designate by $\bar{\Phi}^{j}$ the aggregate level of advertising of station $j$ (namely, $\left.\bar{\Phi}^{j}=\sum_{i=1}^{2}\left(\varphi_{i N P}^{j}+\varphi_{i P}^{j}\right)\right)$ and specify the functional relationship between the listener's utility and the aggregate level of advertising of the station as follows:

$$
U^{j}(x)=\left\{\begin{array}{l}
v_{s}-t_{s} x+\bar{\Phi}^{j} \quad \text { if } \bar{\Phi}^{j} \leq \Phi^{*} \\
v_{s}-t_{s} x-\bar{\Phi}^{j} \quad \text { if } \bar{\Phi}^{j}>\Phi^{*}
\end{array},\right.
$$

where $x$ is the distance of the listener from station $j, U^{j}(x)$ designates her net utility when listening to this station and $\Phi^{*}$ is a certain threshold level of advertising.

There exists empirical support for the utility specification (1) with regard to advertising exposure. For instance van Meurs (1998) examines a study of "channel switching" by Dutch television viewers during commercial breaks. Among the factors most likely to cause switching is the length of the commercial break. This suggests that viewers derive net benefits from

\footnotetext{
${ }^{3}$ If consumers can actively search for information about the products and prices the model is complicated by the need to determine the extent of resources consumers allocate to this activity as a function of the advertising effort selected by the producers. The model has to incorporate, therefore, the searching decision of the consumers in understanding the interaction between producers and stations. Introducing this additional component would distract from the main objective of the paper and interfere with understanding the negotiation process between the producers and the stations. In addition, our model can be easily extended to allow for an external source of information that is available to consumers independent of their search effort. We can incorporate this source by assuming that there is an externally determined probability $\beta_{i}$ that consumers are familiar with brand $i$. The advertising decisions of producer $i$ raise this probability by $G\left(\varphi_{i N P}^{j}+\alpha \varphi_{i P}^{j}\right)$. In our formulation $\beta_{1}=\beta_{2}=0$.
} 
advertising initially. After extended exposure, viewers switch the station or engage in another activity when the net benefit of continued viewing commercials is negative.

If consumers are uncertain about their preferences between the two brands of the product, additional advertising messages help to resolve this uncertainty. The additional information provided by advertising, even if it pertains to only one of the two brands, clarifies to the consumer the attributes of the products and their appropriateness with her preferences. Moreover, listening to a larger number of messages reassures the consumer about making the correct decision and minimizes the extent to which she might regret her consumption choices. (See the classical work of Bell $(1982,1983)$ or the more recent contribution of Inman et al (1997) for a discussion of disappointment and regret effects in determining the consumer's utility function.) In addition to deriving benefits from listening to informative advertising the consumer benefits also from listening to programs aired by the station. The time allotted to such programs has to be reduced if the station allocates more time to advertising. In her decision to listen to a certain station the consumer evaluates how the station's advertising versus programming choice contributes to her utility. Assume, for instance, that the consumer evaluates the station's advertising and programming in terms of the utility function $W(\Phi, \rho)$, where $W_{\Phi}$ and $W_{\rho}$ designate the positive marginal utilities she derives from time allocated to advertising and programming, respectively. Hence, for a given unit of time to be allocated between the two activities, the consumer's preferred choice of level of advertising maximizes the function $w(\Phi) \equiv W(\Phi,(1-\Phi))$. If $W(\cdot)$ satisfies appropriate concavity conditions, there may be a unique interior solution to this maximization. ${ }^{4}$ For moderate levels of aggregate advertising falling short of $\Phi^{*}$ the marginal utility from advertising exceeds the marginal utility from programming, implying that the consumer benefits from increased advertising in this region. If, however, aggregate advertising exceeds $\Phi^{*}$ the marginal utility from programming exceeds that from advertising and the utility of the consumer declines with increased advertising. In the utility

\footnotetext{
${ }^{4}$ If $W_{\Phi} \geq W_{\rho}$ for $\Phi \leq \Phi^{*}$, and $W_{\Phi}<W_{\rho}$ for $\Phi>\Phi^{*}$, and $W_{\Phi \Phi}, W_{\rho \rho}<0, W_{\Phi \Phi} W_{\rho \rho}-W_{\Phi \rho}^{2}>0$ a unique interior solution $\Phi^{*}$ exists. For simplicity, we assume that the threshold level $\Phi^{*}$ is independent of the source of the advertising messages. In particular, if $\bar{\Phi}^{j}<\Phi^{*}$ advertising messages are utility enhancing even if they all come from the same producer. A better assumption would be to condition the consumer's utility on the overall number of messages as well as the extent to which they are diversified across producers. However, since in the sequel we focus only on symmetric equilibria, where all producers advertise equally with each station, the aggregate level of advertising $\bar{\Phi}^{j}$ is divided equally at the equilibrium.
} 
formulation in (1) we have simplified the functional form of $w(\Phi)$ to be piecewise linear, with its maximum still obtained at $\Phi^{*}$.

The specification in (1) implies that consumers are informed of the aggregate level of advertising of the different stations before deciding on their listening behavior. The idea is that stations establish a certain reputation for how often their programs are interrupted to air commercials during different time periods of the day as well as for the kind of products promoted on different programs. For instance, viewers in the early 90's came to expect higher amounts of commercial time on the FOX network than on the other three networks (ABC, CBS, \& NBC) during primetime broadcasts (Source: TV Dimensions 2000, published by Media Dynamics, Inc., p. 51). As well, viewers can anticipate, on average, 7.5\% more advertising time on any of the Big Four broadcasters compared to cable networks (Source: Myers Report, published by Myers Publishing Company, August 10, 2000). They can also anticipate the type of products promoted on the different programs. They expect, for instance, mostly commercials of snacks, soft drinks, and cars on popular sitcoms such as "Friends" or "Ally McBeal," that are watched mostly by teenagers and young adults.

Note that the net utility of the consumer declines the farther away the programming choice of the station from that most preferred by the consumer (i.e. the larger $x$ is). As well, we assume that each consumer can listen to only one station during an interval period of time. She chooses this station in order to obtain a higher level of net utility in (1).

A given station negotiates with each producer prices for placing advertising messages. We designate by $a_{i P}^{j}$ and $a_{i N P}^{j}$ the prices per message that are negotiated between station $j$ and producer $i$ for primetime and non-primetime advertising, respectively. Accordingly, if the producer chooses to advertise at the levels $\varphi_{i P}^{j}$ and $\varphi_{i N P}^{j}$ with station $j$ its payment to this station amounts to $a_{i P}^{j} \varphi_{i P}^{j}+a_{i N P}^{j} \varphi_{i N P}^{j}$. It is noteworthy that our analysis and results remain unchanged if stations can utilize more sophisticated nonlinear pricing schemes, such as a two-part tariff, when charging the producers. In our model, the payment of the producer is determined by negotiations between the parties and not by binding contractual agreements. To model the negotiations between a given producer-station pair we utilize the Nash bargaining solution. This cooperative solution concept implies that the parties to this negotiation agree to split evenly the surplus generated in the trade between them. With a two part tariff pricing scheme, multiple 
combinations of fixed and variable charges may be consistent with the single Nash bargaining solution that governs the negotiations between a given producer-station pair. However, in all of those different combinations the total payment received from the producer is identical and equal to the payment collected with linear pricing. Essentially, the total payment guarantees the station half of the gains from trade generated in the negotiations between the parties.

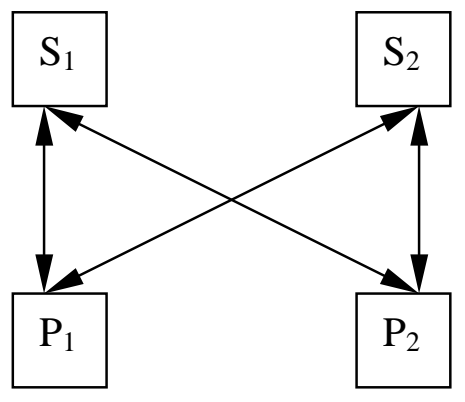

Figure 2: Pairwise Negotiations between Stations $S_{1}, S_{2}$ and Producers $P_{1}, P_{2}$

We assume that each station incurs only fixed costs, $f$, to operate the station, which is unrelated to the number of ads it puts on the air. This assumption is quite reasonable, since most of the variable costs associated with the production of advertising messages are borne by advertising agencies and not the TV or radio stations that broadcast those messages. The production cost of each product producer consists of a per-unit variable cost, $c$, and fixed cost $k$. We designate by $p_{i}$ the price of brand $i$ as selected by this product producer.

We model the game as consisting of two stages. In the first stage, each station negotiates separately with each producer, as illustrated in Figure $2 .^{5}$ The pairwise negotiations among stations and brand producer determine the prices for placing advertising messages, $a_{i N P}^{j}$ and $a_{i P}^{j}$. Simultaneously with the negotiations, each brand producer chooses its level of advertising with each station, $\varphi_{i N P}^{j}$ and $\varphi_{i P}^{j}$, as well as the price it charges from consumers, $p_{i} \cdot{ }^{6}$ In the second

\footnotetext{
${ }^{5}$ Given that there is only a small number of stations and producers, the identity of each is known to other producers and stations in the market. There is no need to consider, therefore, a matching process by which stations become aware of brand producers and vice-versa.

${ }^{6}$ Note that even though advertising levels and prices are chosen simultaneously with the negotiations, those decision variables are not negotiated with stations. Instead, each producer chooses its advertising level and its product price to maximize its profits. This assumption is quite reasonable since it is hard to envision stations taking active part in
} 
stage of the game, consumers decide on their listening and consumption behavior. The choice of the consumer depends upon the aggregate levels of advertising $^{7}$ (aired by stations) and the product prices chosen by the producers in the first stage of the game. Even though we model the negotiations in the first stage of the game as taking place simultaneously with the pricing and advertising decisions of the producers, the analysis can be easily extended to allow for sequential move in this stage of the game, with prices and advertising levels chosen subsequent to the negotiations. In particular, if the outcome of the negotiations between a given producer-station pair remains unobservable to the other producers and stations in the market the results of the analysis remain unaffected with sequential move. As well, it is not unreasonable to assume that producers decide on their advertising simultaneously with the signing of the advertising agreement with the station, since often such agreements specify both the cost and the number of messages to be conveyed by the station.

To model the negotiations between a given producer-station pair we utilize the Nash bargaining solution. This cooperative solution concept implies that the parties to the negotiation agree to split evenly the surplus generated in the trade between them. If $C_{j}$ and $F_{i}$ designate the payoffs that accrue to station $\mathrm{j}$ and product producer $i$, respectively, in case they can reach an agreement and $C_{j}^{-i}$ and $F_{i}^{-j}$ designate their respective payoffs when they are unable to each an agreement (their "outside options") then the gain from trade is equal to $\left(F_{i}+C_{j}\right)-\left(F_{i}^{-j}+C_{j}^{-i}\right)$. The Nash bargaining solution splits this gain (if positive) evenly between the two parties.

The generalized Nash bargaining solution extends this even split to allow for different shares accruing to the parties contingent upon their relative bargaining positions. For instance, if a station has a stronger position in the negotiation its share exceeds one half and that of the producer falls short of one half. To simplify the derivation, we focus on an even split of the gains from trade, and use other parameters of the model to capture the relative bargaining position of the stations vis-à-vis the producers. The parameters that are especially important relate to the extent of competitiveness of the media and product markets, as reflected by the degree of differentiation between stations and products, respectively. In spite of being a

the producers' decisions concerning the pricing of their products or the overall budget they wish to allocate to advertising.

\footnotetext{
${ }^{7}$ As was pointed out earlier, stations establish a certain reputation for their aggregate advertising levels. Consumers use this publicly available information to decide on their listening behavior.
} 
cooperative solution concept, the Nash bargaining solution does not prevent us from capturing the competitive pressures that exist among the parties in the media and product markets. Since the outside options $C_{j}^{-i}$ and $F_{i}^{-j}$ depend upon the nature of competition among product producers and media stations, this competition is reflected in the outcome of the negotiations. Note also that the outcome of non-cooperative bargaining games à la Rubinstein (1982) for instance, converges to the Nash bargaining solution as the probability that negotiations break down tends to zero (see, for instance, Osborne and Rubinstein, 1994, p.310). Hence utilizing this solution concept implements the same outcome that would have obtained by modeling the negotiations explicitly as a sequence of offers and counter-offers between a given stationproducer pair.

To derive the agreement and disagreement payoffs of the negotiations we first identify the segment of the market that is covered by each station and product producer as a function of the number of media messages aired by the stations and the prices paid by consumers. Using the utility specification (1), we can obtain the market share of station $j$ as implied by the advertising decisions of the producers as follows:

$$
\begin{gathered}
\mathrm{X}^{j}=\frac{1}{2}+\frac{\sum_{k=1}^{2}\left(\varphi_{k P}^{j}+\varphi_{k N P}^{j}\right)(-1)^{\delta_{j}}}{2 t_{s}}+\frac{\sum_{k=1}^{2}\left(\varphi_{k P}^{i}+\varphi_{k N P}^{i}\right)(-1)^{\delta_{i}+1}}{2 t_{s}}, \\
\delta_{j}=\left\{\begin{array}{ll}
0 & \text { if } \sum_{k=1}^{2}\left(\varphi_{k P}^{j}+\varphi_{k N P}^{j}\right) \leq \Phi^{*} \\
1 & \text { if } \sum_{k=1}^{2}\left(\varphi_{k P}^{j}+\varphi_{k N P}^{j}\right)>\Phi^{*}
\end{array} \quad i, j=1,2 ; i \neq j .\right.
\end{gathered}
$$

If the aggregate advertising of station $j$ and its competitor each exceeds the threshold level $\Phi^{*}$ then the above derivation implies, in particular, that the market share of station $j$ declines if the producers decide to place additional ads with this station or reduce their advertising with the competing station.

The derivation of the market share of product producer $i$ is complicated by the fact that consumers become informed of the different brands available in the market probabilistically. From our earlier assumption, the probability that the viewers of station $j$ listen to a message pertaining to producer $i$ depends upon the effective units of advertising of this producer with the station, namely $\varphi_{i N P}^{j}+\alpha \varphi_{i P}^{j}$. Designating this effective level by $\varphi_{i E}^{j}$ yields the following 
expression $D_{i}^{j}$ for the expected share of station $j$ 's viewers who end up purchasing brand $i$ in the product market.

$$
D_{i}^{j}=\left\{\left[1-G\left(\varphi_{k E}^{j}\right)\right]+G\left(\varphi_{k E}^{j}\right)\left[\frac{1}{2}+\frac{p_{k}-p_{i}}{2 t_{p}}\right]\right\} G\left(\varphi_{i E}^{j}\right) \quad i, k=1,2 ; i \neq k .
$$

The first term of (3) corresponds to $i$ 's expected share if a given consumer receives messages only about $i$ 's product and not about that of its competitor. The second term corresponds to $i$ 's expected share when the consumer receives messages about both products. In the latter case, the consumer compares the prices of the two products and contingent upon those prices and her location on the distribution of preferences chooses the brand that offers her the higher net utility. This comparison yields the expected market share expressed by the second term of (3). Note that similar to Grossman \& Shapiro (1984), a consumer in our model may end up buying her least preferred brand if she has received only that brand's message. The consumers represented by the first term of (3) purchase brand $i$ irrespective of their location on the distribution of preferences between the two brands. The underlying assumption is that the prices of the products are sufficiently low so that the consumer's willingness to pay for the product, $v_{p}$, exceeds the cost she incurs (product price and transportation cost) irrespective of her location on the line.

\section{Derivation of the Equilibria}

Using the expressions for the market shares we can now state the agreement and disagreement payoffs relevant to the negotiations between station $j$ and producer $i$ as follows:

$$
\begin{gathered}
C_{j}=\sum_{l=1}^{2}\left(a_{l P}^{j} \varphi_{l P}^{j}+a_{l N P}^{j} \varphi_{l N P}^{j}\right)-f \\
F_{i}=\sum_{r=1}^{2} X^{r} D_{i}^{r}\left(p_{i}-c\right)-\sum_{r=1}^{2}\left(a_{i P}^{r} \varphi_{i P}^{r}+a_{i N P}^{r} \varphi_{i N P}^{r}\right)-k, \text { for } i, j=1,2 .
\end{gathered}
$$

The payoff of station $j, C_{j}$, consists of the payments it receives from the producers for airing their advertising messages net of its fixed cost. The payoff of producer $i, F_{i}$, consists of the expected revenues it generates from consumers net of its advertising and production costs. If station $j$ cannot reach an agreement with $i$, it obtains advertising revenues from the remaining 
producer, and producer $i$ can advertise its product with the remaining station. The disagreement payoffs that accrue to the parties in this case are:

$$
\begin{array}{ll}
C_{j}^{-i}=\left(a_{l P}^{j} \varphi_{l P}^{j}+a_{l N P}^{j} \varphi_{l N P}^{j}\right)-f & l=1,2 ; l \neq i \\
F_{i}^{-j}=\tilde{X}^{r} D_{i}^{r}\left(p_{i}-c\right)-\left(a_{i P}^{r} \varphi_{i P}^{r}+a_{i N P}^{r} \varphi_{i N P}^{r}\right)-k & r=1,2 ; r \neq j,
\end{array}
$$

where

$$
\tilde{X}^{r}=\frac{1}{2}+\frac{\sum_{k=1}^{2}\left(\varphi_{k P}^{r}+\varphi_{k N P}^{r}\right)(-1)^{\delta_{r}}}{2 t_{s}}+\frac{\left(\varphi_{l P}^{j}+\varphi_{l N P}^{j}\right)(-1)^{\delta_{j}+1}}{2 t_{s}} .
$$

Notice that when $i$ cannot advertise on station $j$ the market share that accrues to $j$ 's competitor (i.e. station $r$ ) changes according to $\tilde{X}^{r}$. In particular, if both stations still advertise beyond the threshold level $\Phi^{*}$ so that $\delta_{r}=\delta_{j}=1$, the market share of $j$ 's competitor declines since the aggregate advertising on station $j$ decreases when producer $i$ stops advertising with it. $^{8}$

Utilizing (4) and (5), one can derive the added benefit that each party obtains from the negotiations as follows:

$$
\begin{aligned}
& C_{j}-C_{j}^{-i}=a_{i P}^{j} \varphi_{i P}^{j}+a_{i N P}^{j} \varphi_{i N P}^{j} \\
& F_{i}-F_{i}^{-j}=\left[X_{i}^{j} D_{i}^{j}+D_{i}^{r} \frac{\left(\varphi_{i P}^{j}+\varphi_{i N P}^{j}\right)(-1)^{\delta_{j}+1}}{2 t_{s}}\right]\left(p_{i}-c\right)-\left(a_{i P}^{j} \varphi_{i P}^{j}+a_{i N P}^{j} \varphi_{i N P}^{j}\right)
\end{aligned}
$$

where $r \neq j$.

At the Nash bargaining solution the negotiated rates $a_{i P}^{j}$ and $a_{i N P}^{j}$ maximize the product $\left(C_{j}-C_{j}^{-i}\right)\left(F_{i}-F_{i}^{-j}\right)$, implying that the parties split evenly the surplus generated in the negotiations so that $\left(C_{j}-C_{j}^{-i}\right)=\left(F_{i}-F_{i}^{-j}\right)$ and

$$
a_{i P}^{j} \varphi_{i P}^{j}+a_{i N P}^{j} \varphi_{i N P}^{j}=\left[X_{i}^{j} D_{i}^{j}+D_{i}^{r} \frac{\left(\varphi_{i P}^{j}+\varphi_{i N P}^{j}\right)(-1)^{\delta_{j}+1}}{2 t_{s}}\right] \frac{\left(p_{i}-c\right)}{2} .
$$

Note that condition (7) does not uniquely determine the negotiated rates $a_{i P}^{j}$ and $a_{i N P}^{j}$. With a single condition governing the negotiations and two rates to be agreed upon, multiple

\footnotetext{
${ }^{8}$ Recall that consumers make their listening choices in the second stage after stations have already established a certain reputation for their intensities of advertising.
} 
combinations of charges during primetime and non-primetime are consistent with (7). All those combinations guarantee, however, the same total payment to the station as expressed in (7).

The producers choose their level of advertising with the stations and their prices simultaneously with the negotiations, implying that they consider the negotiated rates $a_{i P}^{j}$ and $a_{i N P}^{j}$ fixed when making this choice. ${ }^{9}$ Producer $i$ chooses its level of advertising on station $j$, $\varphi_{i P}^{j}$ and $\varphi_{i N P}^{j}$ and the price of its product $p_{i}$ in order to maximize its agreement payoff, $F_{i}$, thus yielding the following three first order conditions at an interior equilibrium:

$$
\begin{gathered}
\frac{\partial F_{i}}{\partial \varphi_{i P}^{j}}=\left(p_{i}-c\right)\left[\frac{D_{i}^{j} X^{j} G^{\prime}\left(\varphi_{i E}^{j}\right) \alpha}{G\left(\varphi_{i E}^{j}\right)}+\frac{(-1)^{\delta_{j}}}{2 t_{s}}\left(D_{i}^{j}-D_{i}^{r}\right)\right]-a_{i P}^{j}=0, r \neq j \\
\frac{\partial F_{i}}{\partial \varphi_{i N P}^{j}}=\left(p_{i}-c\right)\left[\frac{D_{i}^{j} X^{j} G^{\prime}\left(\varphi_{i E}^{j}\right)}{G\left(\varphi_{i E}^{j}\right)}+\frac{(-1)^{\delta_{j}}}{2 t_{s}}\left(D_{i}^{j}-D_{i}^{r}\right)\right]-a_{i N P}^{j}=0, r \neq j \\
\frac{\partial F_{i}}{\partial p_{i}}=\sum_{k=1}^{2} X^{k} D_{i}^{k}+\sum_{k=1}^{2} X_{i}^{k} \frac{\partial D_{i}^{k}}{\partial p_{i}}\left(p_{i}-c\right)=0 .
\end{gathered}
$$

In the present section, we focus attention only on the derivation of symmetric equilibria. Since stations and producers face identical advertising and production technologies, respectively, and since the distribution of consumer preferences is uniform, it is reasonable to restrict attention to such equilibria. At the symmetric equilibria, each producer diversifies its advertising intensity equally across stations and each station charges producers identical prices. Our analysis can be easily extended to allow for asymmetries between stations or producers. For instance, if the consumers' distribution of preferences between stations is skewed in favor of one of the stations, producers will naturally not allocate their advertising efforts equally across stations in equilibrium. We focus on symmetry since our main objective in the present section is to conduct a comparative statics analysis to evaluate how the equilibrium is affected by the intensity of competition in the product and media markets. In the next section, when we introduce the possibility of exclusive agreements between stations and producers, we allow for some asymmetry in the manner in which stations can treat different producers.

\footnotetext{
${ }^{9}$ Even though the expression for the total payment to station $j$ in (7) depends upon the levels of advertising and the price chosen by producer $i$, this producer does not attempt to manipulate the negotiated payment when choosing its level of advertising and its price. The choice of the decision variables $\varphi_{i}^{j}$ and $p_{i}$ simultaneous with the negotiations guarantee that to be the case.
} 
With a focus on symmetric equilibria, Lemma 1 is a direct implication of conditions (8) (10). The proofs of all lemmas and propositions are included in Appendix 1. Note that since the Nash bargaining solution does not uniquely determine the prices of placing advertisements on the two different time slots of programming, multiple equilibria might arise contingent upon the value of the ratio $a_{i P}^{j} / a_{i N P}^{j}$. This ratio specifies how much more expensive primetime is than non-primetime advertising. In Lemma 1, we specify the advertising decision of each producer as a function of the value of this ratio. The explicit derivation of the negotiated rates $a_{i P}^{j}$ and $a_{i N P}^{j}$ will be included later in the analysis.

\section{Lemma 1}

At the symmetric equilibrium,

(i) if $a_{i P}^{j} / a_{i N P}^{j}<\alpha$ then $\varphi_{i N P}^{j}=0$, and if $a_{i P}^{j} / a_{i N P}^{j}>\alpha$ then $\varphi_{i P}^{j}=0$;

(ii) if $a_{i P}^{j} / a_{i N P}^{j}=\alpha$ then the separate values of $\varphi_{i P}^{j}$ and $\varphi_{i N P}^{j}$ are not uniquely determined. Any combination of values that yields the effective level $\varphi_{i E}^{j}$ satisfying (8) (or equivalently (9)) is consistent with an equilibrium.

(iii) Let $\varphi_{P}=\varphi_{i P}^{j}, \varphi_{N P}=\varphi_{i N P}^{j}, \varphi_{E}=\varphi_{P}+\alpha \varphi_{N P}, a_{P}=a_{i P}^{j}, a_{N P}=a_{i N P}^{j}$, and $(p-c)=\left(p_{i}-c\right)$ for $i, j=1,2$. Then irrespective of the value of the ratio $a_{P} / a_{N P}$ the following conditions characterize the level of advertising and the pricing of each producer at the symmetric equilibrium:

$$
\begin{gathered}
\frac{1}{4}\left[2-G\left(\varphi_{E}\right)\right] G^{\prime}\left(\varphi_{E}\right) \varphi_{E}(p-c)-\left(a_{i P}^{j} \varphi_{i P}^{j}+a_{i N P}^{j} \varphi_{i N P}^{j}\right)=0, \\
\frac{G\left(\varphi_{E}\right)}{2}\left\{\left[2-G\left(\varphi_{E}\right)\right]-\frac{G\left(\varphi_{E}\right)(p-c)}{t_{p}}\right\}=0 .
\end{gathered}
$$

The result reported in Lemma 1 is a direct implication of the perfect substitutability between advertising on primetime and non-primetime in determining the probability of reaching consumers. In our formulation, the functional form of the probability is specified in terms of a single argument $\varphi_{E}$, that measures the effective units of advertising. Such a specification implies that the ratio of the marginal productivities of primetime and non-primetime is a constant 
equal to $\alpha$ (i.e. $G_{\varphi_{P}} / G_{\varphi_{N P}}=\alpha$ ). The corner solution reported in Lemma 1 is implied by this constant ratio. If we specified the probability of reaching consumers in terms of two separate arguments $G\left(\varphi_{N P}, \varphi_{P}\right)$, less than perfect substitutability can be easily obtained by assuming that $G_{\varphi_{P} \varphi_{P}} G_{\varphi_{N P} \varphi_{N P}}-G_{\varphi_{P} \varphi_{N P}}^{2}>0$. For instance, with a Cobb-Douglas probability function $G\left(\varphi_{N P}, \varphi_{P}\right)=\varphi_{P}^{\eta_{1}} \varphi_{N P}^{\eta_{2}}$, less than perfect substitutability requires that $0<\eta_{1}, \eta_{2}<1$ and $\eta_{1}+\eta_{2}<1$. An interior equilibrium with positive levels of advertising on both time slots always prevails in this case. While the perfect substitutability we assume simplifies the derivations, all of our qualitative results remain unaffected with less than perfect substitutability. ${ }^{10}$ In particular, the comparative statics analysis we conduct to evaluate how changes in the parameters affect advertising levels remains qualitatively the same. In the appendix, we derive conditions to guarantee that the solution characterized in Lemma 1 satisfies second order conditions as well as stability of reaction functions. While the concavity of the probability function $G(\cdot)$ guarantees second order conditions we have to impose an additional restriction on $G(\cdot)$ to guarantee stability. We derive this condition in the Appendix to be

$$
\frac{G^{\prime \prime}\left(\varphi_{E}\right)}{G\left(\varphi_{E}\right)}-\left[\frac{G^{\prime}\left(\varphi_{E}\right)}{G\left(\varphi_{E}\right)}\right]^{2}+\frac{1}{2 \varphi_{E}{ }^{2}}<0 .
$$

When all producers increase their advertising symmetrically, condition (13) compares how such an increase affects the marginal benefit from advertising with its effect on the negotiated payment to the station. The stability condition guarantees that the former effect dominates, so that higher levels of advertising by all the producers reduce the marginal contribution of advertising to a larger extent than the reduction in the negotiated payment. ${ }^{11}$

For instance, when $G\left(\varphi_{E}\right)=\varphi_{E}^{\eta}$, where $0<\eta<1$ for concavity, condition (13) holds if $\eta>1 / 2$. The parameter $\eta$ measures the elasticity of the outreach probability $G(\cdot)$. Hence to guarantee the stability condition in the context of this example requires that the outreach elasticity exceeds one half. From this point onwards, we assume (13) to hold.

\footnotetext{
${ }^{10}$ With two separate arguments of $G(\cdot)$, the symmetric equilibrium will be characterized in terms of three different equations rather than the only two we obtain with perfect substitutability (i.e. (11) and (12)).

${ }^{11}$ In fact, if negotiations are modeled alternatively, with a greater (lesser) share of the gains from trade accruing to the station, the negotiated payment is larger (smaller). Consequently, the stability condition in (13) becomes stronger (weaker).
} 
Substituting into (11) the negotiated payment determined by the Nash bargaining solution from (7) yields the result reported in Proposition 1.

\section{Proposition 1}

Let $T(x) \equiv\left[\frac{G^{\prime}(x)}{G(x)}-\frac{1}{2 x}\right]$. At the symmetric equilibrium:

(i) If $a_{i P}^{j} / a_{i N P}^{j}<\alpha$ then

$$
\varphi_{E}= \begin{cases}T^{-1}\left(-\frac{1}{2 \alpha t_{s}}\right) & \text { if } T\left(\alpha \Phi^{*} / 2\right)<-\frac{1}{2 \alpha t_{s}} \\ \alpha \Phi^{*} / 2 & \text { if }-\frac{1}{2 \alpha t_{s}} \leq T\left(\alpha \Phi^{*} / 2\right) \leq \frac{1}{2 \alpha t_{s}} \\ T^{-1}\left(\frac{1}{2 \alpha t_{s}}\right) & \text { if } T\left(\alpha \Phi^{*} / 2\right)>\frac{1}{2 \alpha t_{s}} .\end{cases}
$$

(ii) If $a_{i P}^{j} / a_{i N P}^{j}>\alpha$ then

$$
\varphi_{E}= \begin{cases}T^{-1}\left(-\frac{1}{2 t_{s}}\right) & \text { if } T\left(\Phi^{*} / 2\right)<-\frac{1}{2 t_{s}} \\ \Phi^{*} / 2 & \text { if }-\frac{1}{2 t_{s}} \leq T\left(\Phi^{*} / 2\right) \leq \frac{1}{2 t_{s}} \\ T^{-1}\left(\frac{1}{2 t_{s}}\right) & \text { if } T\left(\Phi^{*} / 2\right)>\frac{1}{2 t_{s}} .\end{cases}
$$

(iii) If $a_{i P}^{j} / a_{i N P}^{j}=\alpha$ then the level of advertising per station satisfies the equation

$$
\begin{array}{ll}
T\left(\varphi_{E}\right)+\frac{\varphi_{N P}+\varphi_{P}}{2 \varphi_{E} t_{s}}=0 & \text { if } \varphi_{N P}+\varphi_{P}<\Phi^{*} / 2 \\
T\left(\varphi_{E}\right)-\frac{\varphi_{N P}+\varphi_{P}}{2 \varphi_{E} t_{s}}=0 & \text { if } \varphi_{N P}+\varphi_{P}>\Phi^{*} / 2 .
\end{array}
$$

Notice that in order to obtain an equilibrium where the aggregate advertising with each station falls short of the threshold level $\Phi^{*}$, it is necessary that the marginal contribution of advertising is sufficiently small so that:

$$
T\left(\varphi_{E}\right)=\left[\frac{G^{\prime}\left(\varphi_{E}\right)}{G\left(\varphi_{E}\right)}-\frac{1}{2 \varphi_{E}}\right]<0
$$


The above inequality implies that each producer is actually harmed with increased advertising. The gross marginal contribution of advertising is measured by $G^{\prime}\left(\varphi_{E}\right)$. However, any surplus generated in the negotiations has to be shared equally between the producer and the station. In particular, the added surplus is split evenly between the parties, translating to an increased negotiated rate of $G\left(\varphi_{E}\right) / 2 \varphi_{E}$ per unit of advertising. The inequality $T\left(\varphi_{E}\right)<0$ implies that even though the gross marginal contribution of advertising is positive (i.e. $G^{\prime}\left(\varphi_{E}\right)>0$ ) its net marginal contribution is negative. This inequality may yield also an inconsistency with the stability condition (13) that was specified earlier. For instance when $G\left(\varphi_{E}\right)=\varphi_{E}^{\eta}$, the stability condition requires that $\eta>1 / 2$, and $T\left(\varphi_{E}\right)<0$ yields the opposite requirement that $\eta<1 / 2$. A similar contradiction is reached if $G\left(\varphi_{E}\right)=\left(1-e^{-\varphi_{E}}\right)$. To avoid such inconsistencies and to guarantee that producers benefit from advertising, we impose an additional restriction that

$$
T\left(\varphi_{E}\right)=\left[\frac{G^{\prime}\left(\varphi_{E}\right)}{G\left(\varphi_{E}\right)}-\frac{1}{2 \varphi_{E}}\right]>0 \text { for all } \varphi_{E} .
$$

The condition implied by (14) is equivalent to the requirement that the elasticity of the outreach probability exceeds 1/2. In Proposition 2 we characterize the symmetric equilibrium under such a restriction.

\section{Proposition 2}

When the elasticity of the outreach probability exceeds $1 / 2$ (i.e. $T\left(\varphi_{E}\right)>0$ ) any symmetric equilibrium is characterized by an aggregate level of advertising by each station that exceeds the threshold level $\Phi^{*}$.

According to the proposition, when the net marginal contribution of advertising is positive the level of advertising that is selected at the equilibrium is viewed by consumers as being excessive. The intensity of advertising that is demanded by each producer yields frequent interruptions of the station's regular programming, which the viewers would have preferred to

avoid. (Since $\sum_{i=1}^{2}\left(\varphi_{i P}^{j}+\varphi_{i N P}^{j}\right) \geq \Phi^{*}$ it follows from (1) that the net utility of each listener declines with the aggregate number of messages aired by the station.) The reason each producer has an incentive to expand its advertising intensity to the extent mentioned above is that such an 
expansion can only benefit the producer when $T(\varphi) \geq 0$. In addition to increasing the probability that consumers become aware of its product, inducing an aggregate level of advertising by the station beyond the threshold level $\Phi^{*}$ improves the negotiating position of producer $i$ vis-à-vis the station. When the aggregate advertising of the station falls short of this threshold level, condition (6) implies that intensified advertising increases the added benefit from agreement that accrues to station $j$ and reduces that of producer $i$. Station $j$ has more to gain from reaching an agreement with $i$ since a disagreement confers a positive externality on station $j$ 's competitor in this case. The larger market share of the competitor that is implied by the disagreement improves the "outside option" available to producer $i$. Specifically, when the market share of $j$ 's competitor increases as a result of $i$ 's disagreement with station $j$, producer $i$ can concentrate his advertising on a single station and still reach a very large audience.

From this point onward we wish to focus only on the case that producers diversify their advertising over the two different time slots of programming so that both $\varphi_{N P}$ and $\varphi_{P}$ are strictly positive. According to Lemma 1 this is possible only if $a_{i P}^{j} / a_{i N P}^{j}=\alpha$, namely only if the ratio of advertising prices coincides with the ratio of the marginal productivities of advertising on the two different time slots. However, from Lemma 1 multiple combinations of $\varphi_{N P}$ and $\varphi_{P}$ may be consistent with an equilibrium when $a_{i P}^{j} / a_{i N P}^{j}=\alpha$. We characterize the different equilibria in terms of a fixed, predetermined level of primetime advertising $\varphi_{P}$. Essentially, such a specification implies that producers have no flexibility to determine their intensity of primetime advertising. If they wish to modify their level of effective advertising they can do so only by adjusting the extent of resources they allocate to non-primetime advertising. This limited flexibility to control the level of advertising on primetime is consistent with the casual observation that the supply of advertising space on primetime $\mathrm{TV}$, for instance, is far more restricted than space available on non-primetime. In the sequel, we investigate how changes in this fixed supply of space on primetime, $\varphi_{P}$, affect the characteristics of the equilibrium. Proposition 2 combined with Lemma 1 imply the following characterization of the symmetric equilibrium when both $\varphi_{N P}$ and $\varphi_{P}$ are positive: 


$$
\begin{gathered}
\varphi_{E}=T^{-1}\left[\frac{1}{2 t_{s}}\left(1-\frac{(1-\alpha) \varphi_{P}}{\varphi_{E}}\right)\right] \text { where } \varphi_{P} \in\left(0, \varphi_{E} / \alpha\right), \\
a_{N P}=\frac{\left[2-G\left(\varphi_{E}\right)\right]^{2}}{8 \varphi_{E}}\left[1+\frac{\varphi_{E}-(\alpha-1) \varphi_{p}}{t_{s}}\right], \\
a_{P}=\alpha a_{N P}, \\
(p-c)=\frac{\left[2-G\left(\varphi_{E}\right)\right] t_{p}}{G\left(\varphi_{E}\right)}, \\
F=\frac{\left[2-G\left(\varphi_{E}\right)\right]^{2} t_{p}}{4}\left[1-\frac{\varphi_{E}-(\alpha-1) \varphi_{P}}{t_{s}}\right]-k, \\
C=\frac{\left[2-G\left(\varphi_{E}\right)\right]^{2} t_{p}}{4}\left[1+\frac{\varphi_{E}-(\alpha-1) \varphi_{P}}{t_{s}}\right]-f .
\end{gathered}
$$

Note that the effective level of advertising $\varphi_{E}$ in (15) is an increasing function of the fixed supply of primetime advertising $\varphi_{P}\left(\right.$ since $T^{\prime}(\cdot)<0$ from (13)). Hence, as stations increase the number of slots that are available for advertising on primetime, the outreach probability of each producer is improved.

Before discussing the properties of the symmetric equilibrium, it is interesting to derive the slopes of the advertising and price reaction functions of the two producers. We can obtain those slopes by total differentiation of the system of equations (8) - (10). (See Appendix.) The complexity of this system requires us to restrict attention to the derivation of the slopes only in the neighborhood of the symmetric equilibrium. We will be able to predict, therefore, how each producer responds to changes in the advertising and pricing decisions of its competitor around the symmetric equilibrium reported in (15) and (16).

\section{Proposition 3}

In the neighborhood of the symmetric equilibrium:

$$
\partial \varphi_{i N P}^{j} / \partial \varphi_{k N P}^{j}=-\partial \varphi_{i N P}^{l} / \partial \varphi_{k N P}^{j}, j \neq l ; i \neq k .
$$

As a result, the aggregate level of advertising of a given producer on both stations 
remains unchanged when its competitor expands slightly its advertising level with one of the stations.

$$
\operatorname{sgn}\left[\partial \varphi_{i N P}^{j} / \partial \varphi_{k N P}^{j}\right]=\operatorname{sgn}\left[\frac{G^{\prime}\left(\varphi_{E}\right)}{2-G\left(\varphi_{E}\right)}-\frac{1}{t_{s}}\right] .
$$

Accordingly, there exists a threshold level of differentiation between stations $t_{s}^{*}$ so that

$$
\partial \varphi_{i N P}^{j} / \partial \varphi_{k N P}^{j}=\left\{\begin{array}{ll}
<0 & \text { if } t_{s}<t_{s}^{*} \\
>0 & \text { if } t_{s}>t_{s}^{*}
\end{array} \quad \text { for } k \neq i .\right.
$$

(iii) When producer $k$ expands its advertising on station $j$, this station loses market share irrespective of whether the competing producer responds by cutting or increasing its own advertising with this station.

(iv) $\quad \partial \varphi_{i N P}^{j} / \partial p_{k}=0, \quad \partial p_{i} / \partial p_{k}=1 / 2$, and

$$
\partial p_{i} / \partial \varphi_{k N P}^{j}=-\frac{t_{p} G^{\prime}\left(\varphi_{E}\right)}{2 G^{2}\left(\varphi_{E}\right)}<0 \quad \text { for } i, j, k=1,2 ; k \neq i
$$

To understand the results reported in the first two parts of Proposition 3, it is useful to highlight the benefit and the cost of a producer's decision to expand its advertising with a given station. On the benefit side, expanded advertising implies that this producer is more likely to reach the viewers of the station. On the cost side, the expanded advertising reduces the market share of this station in comparison to that of the competing station. Both of the above-mentioned marginal benefit and marginal cost are smaller when the competitor increases its level of advertising with the station. The marginal benefit is smaller since the viewers of the station are more likely to be informed about the competing brand as well thus reducing the likelihood of them buying the advertised product of the producer. The marginal cost is smaller since when the competitor advertises more intensely with the given station, the station becomes a less attractive advertising medium anyhow. The decline of its market share that is implied by the producer's decision to increase its advertising with it is not as costly to the producer, as a result. According to (ii) of Proposition 3, the extent of differentiation between the two stations determines which of the above-mentioned two effects on marginal benefit or marginal cost dominates. When stations are only moderately differentiated, it is the effect on marginal benefit that dominates, and when 
stations are highly differentiated, it is the effect on marginal cost that dominates. As a result, when the competitor increases its advertising level with one of the stations, the producer responds by cutting its own advertising with this station in the former case and increasing it in the latter case. According to (i) of the proposition, the competitor's decision to increase its advertising with the station enhances the attractiveness of one station to the same extent that it reduces the attractiveness of the other, thus keeping the overall level of advertising of the producer constant. Part (iii) evaluates the effect of a producer's decision to slightly increase its advertising level with a station on the market share of this station. This part states that irrespective of the direction of the response in the advertising decision of the other producer the market share of this station declines, since the magnitude of the response always falls short of the original increase in the level of advertising.

The last part of the proposition incorporates also the pricing decisions of the producers. This part asserts that the advertising levels selected by a producer are independent of the competitor's product price for small changes around the symmetric equilibrium. On the other hand, the price the producer charges for its product declines if the competitor advertises more intensely with either one of the two stations. Finally, price reaction functions are upward sloping as it is to be expected at the Bertrand equilibrium.

In the next proposition we summarize the properties of the symmetric equilibrium that is expressed by (15) and (16).

\section{Proposition 4}

When the elasticity of the outreach probability is bigger than $1 / 2$, the level of advertising at the symmetric equilibrium is determined by the equation:

$$
T\left(\varphi_{E}\right)-\frac{1}{2 t_{s}}\left[1-\frac{(\alpha-1) \varphi_{P}}{\varphi_{E}}\right]=0 .
$$

As a result,

(i) The effective level of advertising per station is an increasing function of $\alpha, \varphi_{P}$, and $t_{s}$ and is independent of $t_{p}$. Hence the probability of reaching a consumer via a given station increases the more effective and less restrictive the supply of primetime 
advertising and the less competitive the media market. The outreach probability is independent, however, of the extent of competitiveness of the product market.

(ii) The price mark-up of each producer, $p-c$, is an increasing function of $t_{p}$ and a decreasing function of $\alpha, \varphi_{P}$, and $t_{s}$. Hence the more competitive the media market in comparison to the product market the higher the mark-up is and the more effective primetime advertising the smaller this mark-up is.

(iii) The profit that accrues to each station is an increasing function of $t_{p}$. Its relationship to $\alpha, \varphi_{P}$, and $t_{s}$ is ambiguous, however.

The results reported in Proposition 4 are quite intuitive. According to (i), when the media market is more competitive because stations are less differentiated, producers have less to gain from advertising with a certain station. ${ }^{12}$ Since the outreach of competing stations is comparable when they are less differentiated, the benefit from advertising with one particular station declines. As well, (i) states the reasonable result that the outreach of a given station improves when primetime advertising becomes more effective.

The extent to which each producer can mark-up its prices depends upon the extent of competition of both the product and the media markets. The mark-up rises when producers compete less aggressively as a result of greater product differentiation and it declines when consumers are better informed about competing products. When media stations are more differentiated or when primetime advertising is more effective, (i) states that each consumer is more likely to be informed about competing products. More intense competition between the producers and lower prices are implied, therefore, by the better-informed consumer population.

Since the profits of each station are bounded by the extent of producer surplus generated in the product market, a less competitive product market as reflected by larger $t_{p}$ values generates a larger surplus and higher profits to each station. Changes in the parameters $\alpha, \varphi_{P}$ and $t_{s}$ have two counteracting effects on the profits of each station. On the positive side, larger values improve the negotiating position of each station vis-à-vis the producers and on the

\footnotetext{
${ }^{12}$ In a previous version of this paper similar comparative statics results are reported when the extent of competitiveness of a given market is measured in terms of two different variables (number of competitors and the degree of differentiation among them) rather than the single variable we include in the present analysis.
} 
negative side, larger values imply that consumers are better informed (from (ii)) which yields a smaller producer surplus for the stations to extract. The ambiguity reported in (iii) of Proposition 4 is implied by the two counteracting effects mentioned above.

In Proposition 5 we are able to strengthen the comparative statics results when continuing to focus on the case that producers advertise on both time slots of programming.

\section{Proposition 5}

When both $\varphi_{N P}$ and $\varphi_{P}$ are strictly positive and $T\left(\varphi_{E}\right) \varphi_{E}$ is a non-increasing function, then the equilibrium profits of each station decline when $\alpha, \varphi_{P}$ and $t_{s}$ increase.

The additional restriction included in Proposition 5 resolves the ambiguity reported in part (iii) of Proposition 4. The restriction guarantees that any parameter change that improves the outreach probability per station results in lower equilibrium profits of the stations. To explain the result, note, for instance, the implication of a change in $\alpha$ or $\varphi_{P}$. For a fixed level of differentiation between stations, $t_{s}$, the restriction of Proposition 5 establishes in (17) an inverse relationship between the effective level, $\varphi_{E}$, and the overall volume of advertising $\left(\varphi_{N P}+\varphi_{P} \equiv \varphi_{E}-(\alpha-1) \varphi_{P}\right)$ that is demanded by each producer. ${ }^{13}$ Hence, if primetime advertising is more effective or if the supply of advertising space on primetime increases, the inverse relationship implies that each station reduces its overall level of advertising with the station. It appears that producers substitute greater effectiveness for a smaller volume of advertising. Under the restriction of the proposition, the latter reduction is sufficiently large to more than offset the favorable implication of improved effectiveness on the negotiated rate that stations can secure. As a result, the profitability of each station declines. The restriction of the proposition guarantees also that stations are actually worse off as the degree of differentiation between them rises. From Proposition 4, higher values of $t_{s}$ increase the effective level of advertising $\varphi_{E}=\left(\varphi_{N P}+\alpha \varphi_{P}\right)$. For a fixed supply of primetime advertising space, the improved effectiveness can only be accomplished by increasing the intensity of advertising on non-

\footnotetext{
${ }^{13}$ If $\alpha$ increases, the inverse relationship implies that $-\varphi_{P}<\partial \varphi_{N P} / \partial \alpha<0$ and if $\varphi_{P}$ increases the inverse relationship implies that $-\alpha<\partial \varphi_{N P} / \partial \varphi_{P}<-1$. Hence, the producer cuts back significantly on non-primetime advertising so that $\left(\varphi_{N P}+\varphi_{P}\right)$ declines in spite of the rise in $\left(\varphi_{N P}+\alpha \varphi_{P}\right)$.
} 
primetime. In (17), therefore, $\left(\varphi_{E}-(\alpha-1) \varphi_{P}\right)$ increases with $t_{s}$. However, the additional restriction of Proposition 5 guarantees that the ratio $\left(\varphi_{E}-(\alpha-1) \varphi_{P}\right) / t_{s}$ declines as $t_{s}$ increases, thus yielding a smaller profit to each station in (16).

The comparative statics we report in Proposition 5 can provide an additional explanation to the observation that the major TV networks in the U.S. tend to make very similar programming choices. Since the profits of each station decline with $t_{s}$ stations can improve their profitability by reducing the extent of differentiation between them. Note that the reason for this result is completely different from that generating the principle of minimum differentiation in the Hotelling model. With a model of informative advertising, increased differentiation between stations enhances the outreach probability of each station, thus inducing more intense competition between product producers. Since the profits of the media station is determined as a share of the producer surplus generated in the product market, stations may actually be worse off when this producer surplus declines.

The comparative statics can also explain anecdotal evidence from media markets in the U.S. related to advertising prices on primetime TV programs. Buying advertising space on such programs tends to be significantly more expensive than on non-primetime programs. Such pricing is consistent with the reported result that stations are better off by restricting the supply of advertising space that is available on primetime programs.

It is interesting to further interpret the additional condition included in Proposition 5. The restriction that $T\left(\varphi_{E}\right) \varphi_{E}$ is a non-increasing function of $\varphi_{E}$ is equivalent to the condition that

$$
\frac{\partial}{\partial \varphi_{E}}\left(\frac{G^{\prime}\left(\varphi_{E}\right)}{G\left(\varphi_{E}\right)} \varphi_{E}\right) \leq 0 .
$$

Condition (18) states that the elasticity of the outreach probability $G\left(\varphi_{E}\right)$ is a non-increasing function of the effective level of advertising. Hence for a given percentage of increase in $\varphi_{E}$, the implied percentage of increase in the outreach probability $G\left(\varphi_{E}\right)$ is smaller for higher levels of effective advertising. Condition (18) holds, for instance, when $G\left(\varphi_{E}\right)=\varphi_{E}^{\eta}$ or $G\left(\varphi_{E}\right)=\left(1-e^{-\varphi_{E}}\right)$. 
For illustrative purposes consider the case that $G\left(\varphi_{E}\right)=\varphi_{E}^{\eta}$, where $\eta$ measures the elasticity of the outreach probability. Solving for the intensity of advertising at the symmetric equilibrium yields that $\left(\varphi_{P}+\varphi_{N P}\right)=t_{s}(2 \eta-1)$. Hence the level of advertising per station increases with the extent of differentiation between stations and the elasticity of the outreach probability. The level of advertising does not vary, however, with the degree of differentiation between products, $t_{p}$. Note also from (16) that

$$
\begin{gathered}
F=\frac{1}{2}\left[2-G\left(\varphi_{E}\right)\right]^{2} t_{p}(1-\eta)-k, \\
C=\frac{1}{2}\left[2-G\left(\varphi_{E}\right)\right]^{2} t_{p} \eta-f .
\end{gathered}
$$

Hence stations and producers split the producer surplus generated in the product market according to the ratio $\eta: 1-\eta$, yielding a larger share accruing to the media market when the outreach elasticity is bigger. Consistent with the results reported in Proposition 5 each station earns lower profits when either $\alpha, t_{s}$, or $\varphi_{P}$ increase.

\section{Exclusivity Contracts}

Up until now we have not considered the possibility that a given station permits one of the producers to be the only sponsor of some of its programs. Such sole sponsorship is quite common for primetime programs aired on the major TV channels. We focus, therefore, on the case that exclusivity agreements are feasible only for primetime programs. ${ }^{14}$ Hence even when a station has an exclusive agreement with a given producer the competing producer can still advertise with this station on its non-primetime slot. We continue to restrict our attention to a symmetric environment where each producer has an exclusive agreement with one of the stations. $^{15}$

We designate by $\varphi_{N P}^{N X}$ and $\varphi_{N P}^{X}$ the level of non-primetime advertising per station of a producer who does not have an exclusive agreement with the station and of the one who does have such an agreement (superscripts NX and X, respectively). We also designate by $\varphi_{P}^{X}$ the

\footnotetext{
${ }^{14}$ In Appendix 2 we demonstrate that an exclusivity agreement on non-primetime yields the counter-intuitive result that the outreach probability of the excluded producer exceeds that of the producer who is awarded exclusivity.

${ }^{15}$ The present specification implies that each station has an exclusive agreement with a different producer, so that each producer has some presence during primetime. An alternative specification could have been that both stations award exclusivity to the same producer, thus excluding the other producer completely from primetime advertising.
} 
level of primetime advertising of the producer who has the sole sponsorship of the given station's programs during this time slot. Such a specification implies that each station carries $\left(\varphi_{N P}^{N X}+\varphi_{N P}^{X}\right)$ advertising messages on its non-prime time slot and $\varphi_{P}^{X}$ messages on its primetime slot. The payment of the producers per advertising message is designated in a similar manner (i.e. $\left.a_{N P}^{N X}, a_{N P}^{X}, a_{P}^{X}\right)$. Solving for the symmetric equilibria yields the following characterization of the advertising levels: ${ }^{16}$

$$
\begin{aligned}
T\left(\varphi_{N P}^{X}+\alpha \varphi_{P}^{X}\right) & =\frac{(2-y)\left(\varphi_{N P}^{X}+\varphi_{P}^{X}\right)}{2 t_{s}\left(\varphi_{N P}^{X}+\alpha \varphi_{P}^{X}\right)}, \\
T\left(\varphi_{N P}^{N X}\right) & =\frac{\left(2-\frac{1}{y}\right)}{2 t_{s}},
\end{aligned}
$$

where

$$
y \equiv \frac{\left(1-\frac{G\left(\varphi_{N P}^{X}+\alpha \varphi_{P}^{X}\right)}{2}\right) G\left(\varphi_{N P}^{N X}\right)}{\left(1-\frac{G\left(\varphi_{N P}^{N X}\right)}{2}\right) G\left(\varphi_{N P}^{X}+\alpha \varphi_{P}^{X}\right)} .
$$

The prices charged for the two brands are given as:

$$
\left(p^{X}-c\right)=t_{p}\left[\frac{\left(1-\frac{G\left(\varphi_{N P}^{N X}\right)}{2}\right)}{G\left(\varphi_{N P}^{N X}\right)}+\frac{\left(1-\frac{G\left(\varphi_{N P}^{X}+\alpha \varphi_{P}^{X}\right)}{2}\right)}{G\left(\varphi_{N P}^{X}+\alpha \varphi_{P}^{X}\right)}\right]
$$

and the revenues of each station are:

$a_{N P}^{N X} \varphi_{N P}^{N X}+a_{N P}^{X} \varphi_{N P}^{X}+a_{P}^{X} \varphi_{P}^{X}=\left(1-\frac{G\left(\varphi_{N P}^{N X}\right)}{2}\right) G\left(\varphi_{N P}^{X}+\alpha \varphi_{P}^{X}\right)\left[\left(\frac{1}{2}+\frac{\varphi_{N P}^{N X}}{2 t_{s}}\right)+y\left(\frac{1}{2}+\frac{\varphi_{N P}^{X}+\varphi_{P}^{X}}{2 t_{s}}\right)\right] \frac{\left(p^{X}-c\right)}{2}$.

Similar to the derivation in the non-exclusive case, it is possible to derive the slopes of the advertising and price reaction functions when producers are awarded exclusivity rights. (See

\footnotetext{
${ }^{16}$ The derivation can be provided by the authors upon request. Multiple equilibria are implied, once again by (19), when $a_{P}^{X} / a_{N P}^{X}=\alpha$.
} 
Appendix 1.) Those slopes coincide with those derived in the non-exclusive regime (Proposition 3 ) only when $\alpha=1$. When primetime advertising is strictly more effective than non-primetime advertising, so that $\alpha>1$, the magnitude and direction of the slopes with exclusive agreements may be different than when such agreements are not feasible. In particular, in the non-exclusive regime we found that when the competitor increases its advertising level with one of the stations the attractiveness of this station as an advertising medium (i.e. the marginal productivity of advertising with this station) is enhanced to the same extent that the attractiveness of the other station is reduced. As a result, the combined advertising level of the producer on both stations remains unchanged. In the exclusive regime with $\alpha>1$, this might not be the case. For instance, when the competitor increases its advertising level with the station that awards its exclusivity rights, the sum of the marginal productivities of advertising on the two stations may increase as well, thus leading to an increase in the combined level of advertising of the producer with the two stations.

In the next proposition, we derive comparative statics results of the symmetric exclusive equilibrium described by (19) and (20). The results are very similar for those obtained in the non-exclusive regime.

\section{Proposition 6}

Let both $\varphi_{P}^{X}$ and $\varphi_{N P}^{X}$ be strictly positive.

(i) The level of effective advertising of each producer (i.e. $\varphi_{E}^{X}=\varphi_{N P}^{X}+\alpha \varphi_{P}^{X}$ and $\varphi_{N P}^{N X}$ ) are both increasing when the values of $\alpha, t_{s}$, and $\varphi_{P}^{X}$ increase. The price mark-up secured by each producer declines as a result, but the impact of such a change on the revenues of each station is ambiguous. Advertising levels per station are independent of the value of the parameter $t_{p}$. The price mark-up of the producer and the revenues of the station increase with this parameter.

(ii) If primetime advertising is strictly more effective than non-primetime advertising, so that $\alpha>1$, then $\varphi_{E}^{X}>\varphi_{N P}^{N X}$. Otherwise, if $\alpha=1$ then $\varphi_{N P}^{N X}=\varphi_{E}^{X}$.

(iii) If $T(\varphi) \varphi$ is a non-increasing function then $\alpha>1$ implies

$\varphi_{N P}^{X}+\alpha \varphi_{P}^{X}>\varphi_{N P}^{N X}>\varphi_{N P}^{X}+\varphi_{P}^{X}$. 
The results reported in (i) are similar to those derived in Proposition 4 at the nonexclusive equilibria. The level of effective advertising per station increases when the degree of differentiation between stations is bigger, when the effectiveness of primetime advertising rises, or when the producer who is awarded an exclusive contract is offered more advertising space on primetime. Since consumers become better informed, producers are forced to compete more aggressively thus yielding a smaller price mark-up to each. According to (ii) the producer who is awarded an exclusivity contract with the station is more likely to reach the viewers of this station. However, if the condition of (iii) holds, this producer substitutes greater effectiveness for a smaller volume of advertising with the station. As a result, its overall level of advertising with the station falls short of the level selected by the producer who has been excluded from primetime advertising on this station (i.e. $\varphi_{N P}^{N X}>\varphi_{N P}^{X}+\varphi_{P}^{X}$ ). Recall from our earlier discussion that the condition of (iii) implies that the elasticity of the outreach probability is a non-increasing function of the effective level of advertising, $\varphi_{E}$.

A comparison of the system (19) with (17) yields the conclusion reported in Proposition 7.

\section{Proposition 7}

(i) If primetime advertising is strictly more effective than non-prime time advertising, so that $\alpha>1$, then $\left(\varphi_{N P}+\alpha \varphi_{P}\right)>\left(\varphi_{N P}^{X}+\alpha \varphi_{P}^{X}\right)>\varphi_{N P}^{N X}$.

(ii) Otherwise, if $\alpha=1$, then $\left(\varphi_{N P}+\alpha \varphi_{P}\right)=\left(\varphi_{N P}^{X}+\alpha \varphi_{P}^{X}\right)=\varphi_{N P}^{N X}$.

(iii) Price competition between the two products is more intense under the non-exclusive regime so that: $\left(p^{N X}-c\right)<\left(p^{X}-c\right)$ if $\alpha>1$ and $\left(p^{N X}-c\right)=\left(p^{X}-c\right)$ if $\alpha=1$.

(iv) The implication of exclusivity contracts on the revenues of each station is ambiguous.

According to Proposition 7 awarding exclusivity rights to a single producer has no effect on the symmetric equilibria if advertising is equally effective on the two time slots considered. When $\alpha=1$ the extent of advertising per station of each producer is identical. In particular, even a producer that is excluded from primetime advertising with a given station compensates for it by simply expanding its non-primetime advertising so that $\varphi_{N P}^{N X}=\varphi_{N P}^{X}+\varphi_{P}^{X}$. 
Since the level of advertising is identical to that under the non-exclusive arrangement, the extent of competition in the product market is identical as well. When primetime advertising is more effective than non-prime time advertising, exclusivity contracts do have an effect on the incentives of the producers to place advertising messages. The producer who has the sole sponsorship of the primetime program of a given station is more likely to reach the viewers of this station than the one who is excluded from primetime advertising (i.e. $\varphi_{N P}^{X}+\alpha \varphi_{P}^{X}>\varphi_{N P}^{N X}$ ). However, even this producer chooses to reduce its effective level of advertising in comparison to the non-exclusive regime. ${ }^{17}$ Reduced levels of effective advertising implies that viewers are less likely to be informed about the two brands of the product thus yielding less intense price competition among the producers.

To illustrate the results, consider once again the example that $G\left(\varphi_{E}\right)=\varphi_{E}^{\eta}$. Recall that under the non-exclusive regime $\varphi_{N P}+\varphi_{P}=t_{s}(2 \eta-1)$. Under the exclusive regime, however, $\varphi_{N P}^{X}+\varphi_{P}^{X}=t_{s}(2 \eta-1) /(2-y)$ and $\varphi_{N P}^{N X}=t_{s}(2 \eta-1) /\left(2-\frac{1}{y}\right)$, where $y<1$ is as defined in (19). Note that even though the level of advertising of the excluded producer exceeds the level of advertising of the non-excluded one (since $y<1$ and $\varphi_{N P}^{N X}>\varphi_{N P}+\varphi_{P}>\varphi_{N P}^{X}+\varphi_{P}^{X}$ ) the latter is more likely to reach the viewers of the station since $\varphi_{N P}^{X}+\alpha \varphi_{P}^{X}>\varphi_{N P}^{N X}$.

In Appendix 2, we derive a condition to guarantee that each media station has no incentive to deviate from the symmetric exclusive equilibrium described in this section. In order to sustain the exclusive equilibrium, a station should not benefit by offering advertising space on its primetime programs to the producer who is excluded at the equilibrium. Hence, unilateral deviation from exclusion to non-exclusion should not be profitable to the station. ${ }^{18}$ The condition we derive states that upon deviation to non-exclusion, the loss in volume of advertising sold by the deviating station to the formerly excluded producer is sufficiently large to more than offset the higher prices that this station can command for primetime advertising. When the formerly excluded producer is offered advertising space on the station's primetime it substitutes

\footnotetext{
${ }^{17}$ If both stations award exclusivity contracts to the same producer it is possible to show that there is still an overall reduction in the level of advertising. However, while the excluded producer still reduces its advertising effort the producer who has the exclusivity rights on both stations advertises to the same extent as a producer in the nonexclusive regime.

${ }^{18}$ A station that has signed an exclusivity deal with a producer should not have an incentive to renege on the deal by offering space to the other producer as well. If incentives to renege were present, the deal would not have been signed in the first place.
} 
the greater effectiveness for a smaller volume of advertising with the deviating station (if $T(\varphi) \varphi$ is non-increasing in $\varphi$ ). When the decline in volume is sufficiently large, the station loses by deviating from the exclusive equilibrium. Using numerical calculations, we demonstrate that the necessary condition to support the exclusive equilibrium holds for a variety of $\alpha$ and $t_{s}$ values.

\section{Concluding Remarks}

We have presented a model of a differentiated product oligopoly in which producers compete in prices and informative advertising. The media market is incorporated in the model to capture the impact of consumers' media choices on producers' advertising decisions. We have investigated how changes in the parameters of the model affect the negotiations between producers and media stations. We find that the overall outreach probability of advertising is enhanced when the media market is less competitive, when the producer allocates larger resources to primetime advertising, and when the effectiveness of advertising on primetime is significantly larger than on non-primetime. The improved effectiveness of advertising, caused by any one of the above mentioned changes, induces intensified price competition among producers. Media stations may be worse off as a result, since the overall gain from trade that is available in the negotiations with producers declines when producers compete more aggressively in the market. When stations can offer exclusivity rights on primetime, we find that producers have reduced incentives to advertise in comparison to the case that exclusivity agreements are not feasible. Reduced advertising yields less intense price competition, which may benefit both stations and producers. Exclusivity agreements offer a vehicle, therefore, for media stations and product producers to extract additional rents from consumers.

In our analysis we have restricted attention to exclusive agreements on primetime. It is straightforward to extend our investigation to non-primetime exclusive agreements as well. A preliminary analysis yields the counterintuitive result that awarding non-primetime exclusive rights to one producer may actually enhance the overall effectiveness of the rival's advertising campaign. As well, we have assumed that stations cannot offer exclusivity rights to the same producer, and by doing so eliminating the competitor from primetime advertising. If only one producer has access to primetime advertising, the overall outreach probability of this producer rises and that of the competitor declines in comparison to the regime we consider in the present 
paper. Our main conclusions and comparative statics results remain qualitatively similar, however, with such a modification.

To model the negotiations between stations and producers we utilize the Nash bargaining solution. This cooperative solution concept does not prevent us from capturing the competitive pressures that exist in the product and media markets. At the Nash bargaining solution, the negotiating position of each party is determined by its outside option. This outside option is dictated, in turn, by the extent of competition facing the negotiator in its respective market. Utilizing the Nash bargaining concept does not permit us to obtain a unique solution for the prices negotiated between the parties for primetime and non-primetime advertising. Multiple combinations of prices on the two different time slots are consistent with the parties' agreement to split evenly the gains of trade. In spite of the multiplicity, we are able to fully characterize the advertising choices selected by the producers at the equilibrium and to conduct a comparative statics analysis.

In order to simplify the derivation we have modeled both the media and the product markets as differentiated duopolies. Such modeling is the simplest way to introduce competition in each market while still incorporating parameters to measure the extent of competitiveness of the markets. Extending the analysis to allow for an oligopoly model will not change any of our comparative statics results. Essentially, an increase in the extent of differentiation of each market is equivalent, in terms on its effect on the advertising equilibrium, to a reduction in the number of competing firms in an n-firm oligopoly model.

Finally, we assume that the outreach probability function (that relates the effective level of advertising of the producer to the probability that viewers become aware of its product) exhibits perfect substitutability between primetime and non-primetime advertising. Such an assumption has the advantage of simplifying the analysis and the disadvantage of possibly yielding a corner solution in each producer's advertising decision. It is possible to modify the specification of the outreach probability function to allow for less than perfect substitutability. Our qualitative results will not change with such an extension. In particular, the effects of exclusivity agreements or the extent of differentiation between media stations on the advertising choices of the producers remain identical to those derived in the paper. As well, assuming less than perfect substitutability does not resolve the multiplicity of negotiated prices that are consistent with the Nash bargaining solution. 


\section{References}

Bell, D. E. (1982), "Regret in Decision Making Under Uncertainty," Operations Research, 30: 961-981.

Bell, D. E. (1983), "Risk Premiums for Decision Regret," Management Science, 29: 1156-1166.

Bloch, F. and Manceau, D. (1999), "Persuasive Advertising in Hotelling's Model of Product Differentiation," International Journal of Industrial Organization,17: 557-574.

Cirano, M. B. and Moreaux, M. (1999), "Strategic Underinvestment in Informative Advertising: The Cases of Substitutes and Complements," Canadian Journal of Economics, 32(3): 654-672.

Dixit, A. and Norman, V. (1978), “Advertising and Welfare,” Bell Journal of Economics, 9(1): $1-17$.

Dixit, A. and Stiglitz, J. (1977), "Monopolistic Competition and Optimum Product Diversity," American Economic Review, 67(3): 297-308.

Dukes, A. J. (1999), “The Advertising Market in a Product Oligopoly,” mimeo, University of Pittsburgh.

Fruchter, G. (1999), “The Many Player Advertising Game,” Management Science, 45(11): 1609-1611.

Fruchter, G. and Kalish, S. (1997), “Closed-Loop Advertising Strategies in a Duopoly," Management Science, 43(1): 54-63.

Gal-Or, E. (1999), “Mergers and Exclusionary Practices in Health Care Markets," Journal of Economics and Management Strategy, 8(3): 315-350.

Grossman, G. and Shapiro, C. (1984), "Informative Advertising with Differentiated Products," Review of Economic Studies, 51(1): 63-81.

Inman, J. J., Byer, J. S., and Jia, J. (1997), "A Generalized Utility Model of Disappointment and Regret Effects on Post-Choice Valuation," Marketing Science, 16: 97-111.

LeBlanc, G. (1998), “Informative Advertising Competition,” Journal of Industrial Economics, 46(1): 63-77.

Nilssen, T. and Sørgard, L. (2000A), "TV Advertising, Program Quality, and Product Market Oligopoly," University of Oslo Working Paper, April.

Nilssen, T. and Sørgard, L. (2000B), "Strategic Informative Advertising in a TV-Advertising Duopoly," University of Oslo Working Paper, June. 
Osborne, M. and Rubinstein, A. (1994), A Course in Game Theory, Cambridge MA: The MIT Press.

Piga, C.G. (1998), “A Dynamic Model of Advertising and Product Differentiation,” Review of Industrial Organization, 13: 509-522.

Riedman, P. (1998), “Exclusive Internet Advertising Deals' Strategy Questioned," Advertising Age, September 28.

Rubinstein, A. (1982), "Perfect Equilibrium in a Bargaining Model," Econometrica, 50: 97-109.

Siklos, R. (1999), “They Have It All Now,” Business Week, September 20.

Stahl, D. O. (1994), “Oligopolistic Pricing and Advertising," Journal of Economic Theory, 64: 112-177.

van Muers, L. (1998), “Zapp! A Study on Switching Behavior During Commercial Breaks,” Journal of Advertising Research, 38(1): 43-53.

von der Fehr, N-H and Stevik, K. (1998), "Persuasive Advertising and Product Differentiation," Southern Journal of Economics, 65(1): 113-126.

Webster, B.P. (1999), "Barter Syndication," in The Advertising Business: Operations, Creativity, Media Planning, Integrated Communications, ed. J. P. Jones, SAGE Publications. 


\section{Appendix 1 - Proofs of Lemmas and Propositions}

\section{Proof of Lemma 1}

(i) Suppose $a_{i P}^{j} / a_{i N P}^{j}<\alpha$ and $\varphi_{i N P}^{i}>0$ then (9) implies the following condition at the symmetric equilibrium:

$$
\left[\frac{1}{4}\left(2-G\left(\varphi_{E}\right)\right) G^{\prime}\left(\varphi_{E}\right)(p-c)-a_{N P}\right]=0
$$

From (8)

$$
\frac{\partial F_{i}}{\partial \varphi_{i P}^{j}}=\left[\frac{1}{4}\left(2-G\left(\varphi_{E}\right)\right) \alpha-a_{P}\right]>\left[\frac{1}{4}\left(2-G\left(\varphi_{E}\right)\right) \alpha-\alpha a_{N P}\right]=0 .
$$

Hence for any positive level of advertising on non-primetime, the producer can increase its profits by reallocating advertising messages to primetime. As a result the corner solution $\varphi_{N P}^{i}=0$ is implied. The conclusion is reversed if $a_{i P}^{j} / a_{i N P}^{j}>\alpha$.

(ii) When $a_{i P}^{j} / a_{i N P}^{j}=\alpha$ first order conditions (8) and (9) are equivalent and yield an identical solution for the effective level of advertising $\varphi_{E}$. The separate levels of $\varphi_{P}$ and $\varphi_{N P}$ are not uniquely determined in this case.

(iii) When either $\varphi_{N P}$ or $\varphi_{P}$ are zero, condition (11) is implied by multiplying either (8) or (9), respectively, by the level of advertising that is still positive on one of the time slots. If both levels are positive (when $a_{i P}^{j} / a_{i N P}^{j}=\alpha$ ) the condition is obtained by multiplying (8) and (9) by the corresponding level of advertising on each time slot and adding the two equations together. Condition (12) is obtained by substituting symmetry into (10).

Q.E.D.

\section{Second Order Conditions}

At the symmetric equilibrium,

$$
\begin{gathered}
\frac{\partial^{2} F_{i}}{\left(\partial \varphi_{i P}^{j}\right)^{2}}=\left(1-\frac{G}{2}\right) \frac{\alpha}{2}\left[\alpha G^{\prime \prime}-2 \frac{G^{\prime}}{t_{s}}\right](p-c)<0, \\
\frac{\partial^{2} F_{i}}{\left(\partial \varphi_{i N P}^{j}\right)^{2}}=\left(1-\frac{G}{2}\right) \frac{1}{2}\left[G^{\prime \prime}-\frac{2 G^{\prime}}{t_{s}}\right](p-c)<0,
\end{gathered}
$$




$$
\begin{gathered}
\frac{\partial^{2} F_{i}}{\partial p_{i}^{2}}=-\frac{G^{2}}{t_{p}}<0, \\
\frac{\partial^{2} F_{i}}{\partial \varphi_{i P}^{j} \partial p_{i}}=\frac{\partial^{2} F_{i}}{\partial \varphi_{i N P}^{j} \partial p_{i}}=0, \\
\frac{\partial^{2} F_{i}}{\partial \varphi_{i P}^{j} \partial \varphi_{i N P}^{j}}=\left(1-\frac{G}{2}\right) \frac{1}{2}\left[G^{\prime \prime} \alpha-\frac{(1+\alpha) G^{\prime}}{t_{s}}\right](p-c)<0 .
\end{gathered}
$$

Consistent with the corner solution reported in Lemma 1, it is easy to show that one of the second order conditions that are necessary to guarantee that both $\varphi_{P}$ and $\varphi_{N P}$ are positive is violated. Specifically,

$$
R_{2}=\left[\frac{\partial^{2} F_{i}}{\left(\partial \varphi_{i P}^{j}\right)^{2}} \frac{\partial^{2} F_{i}}{\left(\partial \varphi_{i N P}^{j}\right)^{2}}-\left(\frac{\partial^{2} F_{i}}{\partial \varphi_{i P}^{j} \partial \varphi_{i N P}^{j}}\right)^{2}\right]=-\left[\left(1-\frac{G}{2}\right) \frac{(p-c)}{2} \frac{G^{\prime}}{t_{s}}\right]^{2}(\alpha-1)^{2} \leq 0,
$$

thus violating the requirement that the principal minor of size two is positive. This requirement is necessary to guarantee that the Hessian of second order derivatives is negative definite. From Lemma 1 two conditions (either (8) and (10) or (9) and (10)) characterize the interior equilibrium. To guarantee that second order conditions hold the Hessian of second order derivatives (of size $2 \times 2$ ) is negative definite. Evaluating the principal minors of size one and two yields the appropriate sign $(-1)^{\mathrm{k}}$ as implied by (A.1) - (A.4) and concavity of $G(\cdot)$.

\section{Stability}

Plugging into (11) the Nash bargaining solution for the total payment of each station yields the following system at the symmetric equilibrium:

$$
\begin{gathered}
M\left(\varphi_{E}, p\right) \equiv \frac{G^{\prime}\left(\varphi_{E}\right)}{G\left(\varphi_{E}\right)}-\frac{1}{2 \varphi_{E}}-\frac{1}{2 t_{s}}\left[1-\frac{(\alpha-1) \varphi_{P}}{\varphi_{E}}\right]=0, \\
L\left(p, \varphi_{E}\right)=\left(2-G\left(\varphi_{E}\right)\right)-\frac{G\left(\varphi_{E}\right)(p-c)}{t_{p}}=0 .
\end{gathered}
$$

For stability of reaction functions ${ }^{19}: M_{\varphi_{E}}<0, L_{p}<0$, and $\left[M_{\varphi_{E}} L_{p}-M_{p} L_{\varphi_{E}}\right]>0$.

\footnotetext{
${ }^{19}$ Subscripts $\varphi_{E}$ and $p$ designate partial derivatives. As well, distinguish the partial derivative with respect to price (lower case $p$ ) from the designation of primetime (upper case $P$.)
} 
Let $T\left(\varphi_{E}\right)=\frac{G^{\prime}\left(\varphi_{E}\right)}{G\left(\varphi_{E}\right)}-\frac{1}{2 \varphi_{E}}$, then

$$
M_{\varphi_{E}}= \begin{cases}T^{\prime}\left(\varphi_{E}\right) \quad \text { if } \quad a_{P} / a_{N P}>\alpha \text { or } a_{P} / a_{N P}<\alpha \\ T^{\prime}\left(\varphi_{E}\right)-\frac{(\alpha-1) \varphi_{P}}{2 t_{s} \varphi_{E}^{2}} & \text { for a given } \varphi_{P} \in\left[0, \varphi_{E} / \alpha\right] \\ \text { when } a_{P} / a_{N P}=\alpha .\end{cases}
$$

Hence a necessary condition for $M_{\varphi_{E}}<0$ is that $T^{\prime}\left(\varphi_{E}\right)<0$.

$$
\begin{gathered}
L_{p}=-\frac{G\left(\varphi_{E}\right)}{t_{p}} \\
M_{p}=0 \\
L_{\varphi_{E}}=-G^{\prime}\left(\varphi_{E}\right)\left[1+\frac{(p-c)}{t_{p}}\right] .
\end{gathered}
$$

From (A.8) it follows that stability is guaranteed provided that:

$$
\left[\frac{G \cdot G^{\prime \prime}-\left(G^{\prime}\right)^{2}}{G^{2}}+\frac{1}{2 \varphi_{E}^{2}}\right]<0 \text {. }
$$

Note that the concavity of $G\left(\varphi_{E}\right)$ is insufficient to guarantee the stability condition (A.9). Only if the elasticity of the function $G$ (i.e. $\frac{G^{\prime}}{G} \varphi_{E}$ ) and that of its slope (i.e. $-\frac{G^{\prime \prime}}{G^{\prime}} \varphi_{E}$ ) are sufficiently high will reaction function stability hold.

\section{Proof of Proposition 1}

(i) When $a_{i P}^{j} / a_{i N P}^{j}<\alpha$ substituting (7) into (8) yields:

$$
\frac{\partial F_{i}}{\partial \varphi_{i P}^{j}}=\left(p_{i}-c\right)\left\{X_{i}^{j} D_{i}^{j} T\left(\varphi_{i E}^{j}\right)+\frac{(-1)^{\delta_{j}}}{2 \alpha t_{s}}\left[D_{i}^{j}-\frac{D_{i}^{r}}{2}\right]\right\} .
$$

Assuming a solution with $\sum_{i=1}^{2} \varphi_{i P}^{j}<\Phi^{*}$ so that $\delta_{j}=0$ and substituting symmetry yields the condition:

$$
\frac{\partial F_{i}}{\partial \varphi_{i P}^{j}}=(p-c) \frac{D}{2}\left[T\left(\varphi_{E}\right)+\frac{1}{2 \alpha t_{s}}\right]=0 \Rightarrow \varphi_{E}=T^{-1}\left(-\frac{1}{2 \alpha t_{s}}\right) .
$$


Given the stability condition $T^{\prime}\left(\varphi_{E}\right)<0$, and the above condition holds only if $T\left(\alpha \Phi^{*} / 2\right)<-1 /\left(2 \alpha t_{s}\right)$. If $T\left(\alpha \Phi^{*} / 2\right) \geq-1 /\left(2 \alpha t_{s}\right)$ then $\partial F_{i} / \partial \varphi_{i P}^{j}>0$ everywhere in this region, implying setting the highest level $\varphi_{P}=\Phi^{*} / 2$ that is consistent with the region.

Assuming a solution with $\sum_{i=1}^{2} \varphi_{i P}^{j}>\Phi^{*}$ so that $\delta_{j}=1$ and substituting symmetry yields the condition:

$$
\frac{\partial F_{i}}{\partial \varphi_{i P}^{j}}=(p-c) \frac{D}{2}\left[T\left(\varphi_{E}\right)-\frac{1}{2 \alpha t_{s}}\right]=0 \Rightarrow \varphi_{E}=T^{-1}\left(\frac{1}{2 \alpha t_{s}}\right) .
$$

Since $T^{\prime}\left(\varphi_{E}\right)<0$ the above condition holds only if $T\left(\alpha \Phi^{*} / 2\right)>1 /\left(2 \alpha t_{s}\right)$. If $T\left(\alpha \Phi^{*} / 2\right) \leq 1 /\left(2 \alpha t_{s}\right)$ then $\partial F_{i} / \partial \varphi_{i P}^{j}<0$ everywhere in the region, implying setting the lowest advertising intensity consistent with the region (i.e. $\varphi_{P}=\Phi^{*} / 2$ ).

(ii) When $a_{i P}^{j} / a_{i N P}^{j}>\alpha$ substituting (7) into (9) yields a similar derivation to part (i).

(iii) When $a_{i P}^{j} / a_{i N P}^{j}=\alpha$ combining (8) and (9) after multiplying each by the appropriate level of advertising ( $\varphi_{i P}^{j}$ and $\varphi_{i N P}^{j}$, respectively) and substituting (7) into the combined expression yields this part of the proposition.

Q.E.D.

\section{Proof of Proposition 3}

For fixed primetime space available on each station (i.e. $\varphi_{1 P}^{j}=\varphi_{2 P}^{j}=\varphi_{P} ; j=1,2$ ), substitute (7) into (8)-(10) to obtain the following system of equations to determine $\varphi_{i N P}^{1}, \varphi_{i N P}^{2}$ and $p_{i}$.

$$
\begin{aligned}
& \frac{\partial F_{i}}{\partial \varphi_{i N P}^{j}}=\left(p_{i}-c\right)\left[X^{j} D_{i}^{j} \varphi_{i E}^{j} T\left(\varphi_{i E}^{j}\right)-\frac{\left(\varphi_{i E}^{j}-(\alpha-1) \varphi_{P}\right)\left(2 D_{i}^{j}-D_{i}^{r}\right)}{4 t_{s}}\right]=0 \quad j=1,2 ; j \neq r \\
& \frac{\partial F_{i}}{\partial p_{i}}=X^{1} D_{i}^{1}+X^{2} D_{i}^{2}-\left[\frac{G\left(\varphi_{1 E}^{1}\right) G\left(\varphi_{2 E}^{1}\right) X^{1}}{2 t_{p}}+\frac{G\left(\varphi_{1 E}^{2}\right) G\left(\varphi_{2 E}^{2}\right) X^{2}}{2 t_{p}}\right]\left(p_{i}-c\right)=0 .
\end{aligned}
$$

The above system of first order conditions determines the decision variables of producer $i$ in terms of those chosen by $k$ as follows: $\varphi_{i N P}^{j}=f^{j}\left(\varphi_{k N P}^{1}, \varphi_{k N P}^{2}, p_{k}\right) j=1,2$ and $p_{i}=g\left(\varphi_{k N P}^{1}, \varphi_{k N P}^{2}, p_{k}\right)$. The slopes of the reaction functions $f^{j}$ and $g$ can be derived by total 
differentiation of (A.10). In the neighborhood of the symmetric equilibrium we obtain the following system:

$$
\left(\begin{array}{ccc}
A & B & 0 \\
B & A & 0 \\
0 & 0 & -\frac{G^{2}\left(\varphi_{E}\right)}{t_{p}}
\end{array}\right)\left(\begin{array}{l}
d \varphi_{i N P}^{1} \\
d \varphi_{i N P}^{2} \\
d p_{i}
\end{array}\right)=\left(\begin{array}{ccc}
C & -C & 0 \\
-C & C & 0 \\
\frac{G^{\prime}\left(\varphi_{E}\right)}{2} & \frac{G^{\prime}\left(\varphi_{E}\right)}{2} & -\frac{G^{2}\left(\varphi_{E}\right)}{2 t_{p}}
\end{array}\right)\left(\begin{array}{l}
d \varphi_{k N P}^{1} \\
d \varphi_{k N P}^{2} \\
d p_{k}
\end{array}\right),
$$

where

$$
\begin{aligned}
& A \equiv-\frac{\left[2-G\left(\varphi_{E}\right)\right]^{2} t_{p}}{4 t_{s}}\left[\varphi_{E} T\left(\varphi_{E}\right)+\frac{G^{\prime}\left(\varphi_{E}\right)\left(\varphi_{E}-(\alpha-1) \varphi_{P}\right)}{2 G\left(\varphi_{E}\right)}+\frac{(\alpha-1) \varphi_{P}}{2 \varphi_{E}}-t_{s} \varphi_{E} T^{\prime}\left(\varphi_{E}\right)\right]<0, \\
& B \equiv \frac{\left[2-G\left(\varphi_{E}\right)\right]^{2} t_{p}}{4 t_{s}}\left[\varphi_{E} T\left(\varphi_{E}\right)+\frac{G^{\prime}\left(\varphi_{E}\right)\left(\varphi_{E}-(\alpha-1) \varphi_{P}\right)}{2 G\left(\varphi_{E}\right)}\right]>0, \\
& C \equiv \frac{\left[2-G\left(\varphi_{E}\right)\right]^{2} t_{p}}{8 t_{s}}\left[\frac{1}{t_{s}}-\frac{G^{\prime}\left(\varphi_{E}\right)}{2-G\left(\varphi_{E}\right)}\right]\left(\varphi_{E}-(\alpha-1) \varphi_{P}\right) .
\end{aligned}
$$

Note that the stability condition $T^{\prime}\left(\varphi_{E}\right)<0$ guarantees that $|A|>|B|$. Solving (A.11) we obtain:

$$
\begin{gathered}
\frac{\partial \varphi_{i N P}^{1}}{\partial \varphi_{k N P}^{1}}=\frac{C}{(A-B)}, \\
\frac{\partial \varphi_{i N P}^{2}}{\partial \varphi_{k N P}^{1}}=\frac{-C}{(A-B)}, \\
\frac{\partial p_{i}}{\partial \varphi_{k N P}^{1}}=-\frac{t_{p} G^{\prime}\left(\varphi_{E}\right)}{2 G^{2}\left(\varphi_{E}\right)}, \\
\frac{\partial \varphi_{i N P}^{j}}{\partial p_{k}}=0 \\
\frac{\partial p_{i}}{\partial p_{k}}=\frac{1}{2} .
\end{gathered}
$$

Parts (i), (ii), and (iv) of the proposition follow directly from (A.12). To prove part (iii), note that when producer $k$ raises its advertising with station 1 and producer $i$ responds by increasing its advertising with this station as well (when $C<0$ ) the market share of station 1 will obviously decline since the overall number of messages carried by this station increases relative to station 2. If, however, producer $i$ responds by cutting its advertising with station 1 , the market share of 
station 1 will decline as long as $1+\frac{C}{A-B}>-\frac{C}{A-B}$, or equivalently, if $\frac{-C}{A-B}<\frac{1}{2}$. It is easy to show that the last inequality holds even when $C>0$.

Q.E.D.

\section{Proof of Proposition 4}

(i) Total differentiation of (15) yields:

$$
\left[T^{\prime}\left(\varphi_{E}\right)-\frac{(\alpha-1) \varphi_{P}}{2 t_{s} \varphi_{E}^{2}}\right] d \varphi_{E}+\frac{1}{2 t_{s}^{2}}\left[1-\frac{(\alpha-1) \varphi_{P}}{\varphi_{E}}\right] d t_{s}+\frac{\varphi_{P}}{2 t_{s} \varphi_{E}} d \alpha+\frac{(\alpha-1) d \varphi_{P}}{2 t_{s} \varphi_{E}}=0 .
$$

The comparative statics follow since $T^{\prime}\left(\varphi_{E}\right)<0$.

(ii), (iii) The comparative statics with respect to $t_{p}$ are implied by direct differentiation with respect to $t_{p}$. The results reported in part (i) assist in the comparative statics with respect to $t_{s}$, $\alpha$, and $\varphi_{P}$.

Q.E.D.

\section{Proof of Proposition 5}

From (15) if both $\varphi_{P}$ and $\varphi_{N P}$ are positive $T\left(\varphi_{E}\right) \varphi_{E}-\frac{\left(\varphi_{N P}+\varphi_{P}\right)}{2 t_{s}}=0$.

From Proposition 3, $\varphi_{E}$ increases when $t_{s}, \alpha$, or $\varphi_{P}$ increase. If $T\left(\varphi_{E}\right) \varphi_{E}$ is a non-increasing function, it follows that $\left(\varphi_{N P}+\varphi_{P}\right) / 2 t_{s}$ is declining when $t_{s}, \alpha$, or $\varphi_{P}$ increases. Utilizing this conclusion in the expression derived for the profits of each station in (16) yields the result.

Q.E.D.

\section{Derivation of Advertising and Price Reaction Functions in Exclusive Regime}

For fixed advertising space on primetime on each station (i.e. $\varphi_{i P}^{1}=\varphi_{i P}^{2}=\varphi_{P}$ ), producer $i$ chooses its non-primetime advertising levels with the station that awards it exclusivity and the one that does not (i.e. $\varphi_{i N P}^{X}$ and $\varphi_{i N P}^{N X}$, respectively) as well as its price, $p_{i}$, to maximize its profits. Deriving first-order conditions, while incorporating the expressions for the negotiated rates yields the following three conditions: 


$$
\begin{gathered}
\frac{\partial F_{i}}{\partial \varphi_{i N P}^{X}}=\left[\left(D_{i}^{j}-2 D_{i}^{i}\right)\left(\varphi_{P}+\varphi_{i N P}^{X}\right)+X^{i} D_{i}^{i} \varphi_{i E}^{X} T\left(\varphi_{i E}^{X}\right)\right]\left(p_{i}-c\right)=0 \\
\left.\frac{\partial F_{i}}{\partial \varphi_{i N P}^{N X}}=\left[\left(D_{i}^{i}-2 D_{i}^{j}\right) \varphi_{i N P}^{N X}\right)+X^{j} D_{i}^{j} \varphi_{i N P}^{N X} T\left(\varphi_{i N P}^{N X}\right)\right]\left(p_{i}-c\right)=0 \\
\frac{\partial F_{i}}{\partial p_{i}}=X^{1} D_{i}^{1}+X^{2} D_{i}^{2}-\frac{p_{i}-c}{2 t_{p}}\left[X^{i} G\left(\varphi_{i E}^{X}\right) G\left(\varphi_{j N P}^{N X}\right)+X^{j} G\left(\varphi_{j E}^{X}\right) G\left(\varphi_{i N P}^{N X}\right)\right]=0
\end{gathered}
$$

where

$$
\begin{gathered}
D_{i}^{i}=\left[\left(1-G\left(\varphi_{j N P}^{N X}\right)+G\left(\varphi_{j N P}^{N X}\right)\left(\frac{1}{2}+\frac{p_{j}-p_{i}}{2 t_{p}}\right)\right] G\left(\varphi_{i E}^{X}\right),\right. \\
D_{i}^{j}=\left[\left(1-G\left(\varphi_{j E}^{X}\right)+G\left(\varphi_{j E}^{X}\right)\left(\frac{1}{2}+\frac{p_{j}-p_{i}}{2 t_{p}}\right)\right] G\left(\varphi_{i N P}^{N X}\right),\right. \\
X^{i}=\frac{1}{2}-\frac{\varphi_{i N P}^{X}+\varphi_{j N P}^{N X}}{2 t_{s}}+\frac{\varphi_{j N P}^{X}+\varphi_{i N P}^{N X}}{2 t_{s}},
\end{gathered}
$$

for $i, j=1,2 ; i \neq j$.

Total differentiation of (A.13) and evaluation of the total derivative in the neighborhood of the symmetric equilibrium yields the following system:

$$
\left(\begin{array}{ccc}
A & B & C \\
B^{\prime} & A^{\prime} & \frac{-\varphi_{N P}^{N X} C}{\varphi_{P}+\varphi_{N P}^{X}} \\
D & \frac{-D\left(\frac{1}{t_{s}}-\frac{G^{\prime}\left(\varphi_{N P}^{N X}\right)}{2 \varphi_{N P}^{N X}}\right)}{\left(\frac{1}{t_{s}}-\frac{G^{\prime}\left(\varphi_{E}^{X}\right)}{2 G\left(\varphi_{E}^{X}\right)}\right)} & \frac{-G\left(\varphi_{N P}^{N X}\right) G\left(\varphi_{E}^{X}\right)}{t_{p}}
\end{array}\right)\left(\begin{array}{c}
d \varphi_{i N P}^{X} \\
d \varphi_{i N P}^{N X} \\
d p_{i}
\end{array}\right)=\left(\begin{array}{ccc}
R & R^{\prime} & W \\
V & V^{\prime} & \frac{-W \varphi_{N P}^{N X}}{\left(\varphi_{P}+\varphi_{N P}^{X}\right) y} \\
S & S^{\prime} & \frac{-G\left(\varphi_{N P}^{N X}\right) G\left(\varphi_{E}^{X}\right)}{2 t_{p}}
\end{array}\right)\left(\begin{array}{c}
d \varphi_{j N P}^{N X} \\
d \varphi_{j N P}^{X} \\
d p_{j}
\end{array}\right)
$$

where

$$
\begin{aligned}
& A \equiv-\frac{(p-c) D_{i}^{i}}{2 t_{s}}\left[\frac{2-y}{2}\left(1-\frac{\varphi_{P}+\varphi_{N P}^{X}}{\varphi_{E}^{X}}+\frac{\varphi_{P}+\varphi_{N P}^{X}}{t_{s}}\right)+\frac{y\left(\varphi_{P}+\varphi_{N P}^{X}\right)}{4 \varphi_{E}^{X}}\left(1+\frac{(2-y)\left(\varphi_{P}+\varphi_{N P}^{X}\right)}{t_{s}}\right)-\varphi_{E}^{X} T^{\prime}\left(\varphi_{E}^{X}\right) t_{s}\right], \\
& B \equiv \frac{(p-c) D_{i}^{i}}{2 t_{s}}\left[\frac{2-y}{2}\left(\frac{\varphi_{P}+\varphi_{N P}^{X}}{t_{s}}\right)+\frac{y\left(\varphi_{P}+\varphi_{N P}^{X}\right)}{4 \varphi_{N P}^{N X}}\left(1+\frac{\varphi_{N P}^{N X}\left(2-\frac{1}{y}\right)}{t_{s}}\right)\right],
\end{aligned}
$$




$$
\begin{aligned}
& C \equiv \frac{(y-1)(p-c) G\left(\varphi_{N P}^{N X}\right) G\left(\varphi_{E}^{X}\right)\left(\varphi_{P}+\varphi_{N P}^{X}\right)}{8 t_{p} t_{s}}, \\
& A^{\prime} \equiv-\frac{(p-c) D_{i}^{i}}{2 t_{s}}\left[\frac{(2 y-1) \varphi_{N P}^{N X}}{2 t_{s}}+\frac{1}{4}\left(1+\frac{\left(2-\frac{1}{y}\right) \varphi_{N P}^{N X}}{t_{s}}\right)-y t_{s} \varphi_{N P}^{N X} T^{\prime}\left(\varphi_{N P}^{N X}\right)\right] \\
& B^{\prime} \equiv \frac{(p-c) D_{i}^{i}}{2 t_{s}}\left[\frac{(2 y-1) \varphi_{N P}^{N X}}{2 t_{s}}+\frac{\varphi_{N P}^{N X}}{4 \varphi_{E}^{X}}\left(1+\frac{(2-y)\left(\varphi_{P}+\varphi_{N P}^{X}\right)}{t_{s}}\right)\right], \\
& D \equiv \frac{\left[2-G\left(\varphi_{N P}^{N X}\right)\right] G\left(\varphi_{E}^{X}\right)(y-1)}{4}\left(\frac{1}{t_{s}}-\frac{G^{\prime}\left(\varphi_{E}^{X}\right)}{2 G\left(\varphi_{E}^{X}\right)}\right), \\
& R \equiv \frac{(p-c) G\left(\varphi_{E}^{X}\right)\left(\varphi_{P}+\varphi_{N P}^{X}\right)}{8 t_{s}}\left[\frac{(2-y)\left[2-G\left(\varphi_{N P}^{N X}\right)\right]}{t_{s}}-G^{\prime}\left(\varphi_{N P}^{N X}\right) y\right] \text {, } \\
& R^{\prime} \equiv-\frac{(p-c) G\left(\varphi_{E}^{X}\right)\left(\varphi_{P}+\varphi_{N P}^{X}\right)}{8 t_{s}}\left[\frac{(2-y)\left[2-G\left(\varphi_{N P}^{N X}\right)\right]}{t_{s}}-\frac{G^{\prime}\left(\varphi_{E}^{X}\right) G\left(\varphi_{N P}^{N X}\right)}{G\left(\varphi_{E}^{X}\right)}\right] \\
& W \equiv \frac{(p-c) G\left(\varphi_{E}^{X}\right) G\left(\varphi_{N P}^{N X}\right)\left(\varphi_{P}+\varphi_{N P}^{X}\right)(y-1)}{8 t_{p} t_{s}}, \\
& V \equiv-\frac{(p-c) \varphi_{N P}^{N X} G\left(\varphi_{E}^{X}\right)}{8 t_{s}}\left[\frac{\left(2-\frac{1}{y}\right) G\left(\varphi_{N P}^{N X}\right)\left[2-G\left(\varphi_{E}^{X}\right)\right]}{t_{s} G\left(\varphi_{E}^{X}\right)}-G^{\prime}\left(\varphi_{N P}^{N X}\right)\right], \\
& V^{\prime} \equiv \frac{(p-c) \varphi_{N P}^{N X} G\left(\varphi_{N P}^{N X}\right)}{8 t_{s}}\left[\frac{\left(2-\frac{1}{y}\right)\left[2-G\left(\varphi_{E}^{X}\right)\right]}{t_{s}}-\frac{G^{\prime}\left(\varphi_{E}^{X}\right)}{y}\right] \text {, } \\
& S \equiv-\frac{(y-1) G\left(\varphi_{E}^{X}\right)}{4}\left[\frac{\left[2-G\left(\varphi_{N P}^{N X}\right)\right]}{t_{s}}-\frac{G^{\prime}\left(\varphi_{N P}^{N X}\right)}{2}\right]+\frac{(1+y) G^{\prime}\left(\varphi_{N P}^{N X}\right) G\left(\varphi_{E}^{X}\right)}{4 G\left(\varphi_{N P}^{N X}\right)}, \\
& S^{\prime} \equiv \frac{(y-1) G\left(\varphi_{E}^{X}\right)}{4}\left[\frac{\left[2-G\left(\varphi_{N P}^{N X}\right)\right]}{t_{s}}-\frac{G^{\prime}\left(\varphi_{E}^{X}\right) G\left(\varphi_{N P}^{N X}\right)}{2 G\left(\varphi_{E}^{X}\right)}\right]+\frac{(1+y) G^{\prime}\left(\varphi_{E}^{X}\right)}{4} \text {. }
\end{aligned}
$$

It can be shown that $A, C, A^{\prime}, W<0<B, B^{\prime}$.

For stability, the matrix on the LHS of (A.14) should be negative definite, implying that $A, A^{\prime}<0 ; A A^{\prime}-B B^{\prime}>0$; and the determinant of the matrix is negative. Note that system (A.14) reduces to the system (A.11) when $\alpha=1$ (since $y=1$ in this case). Hence the slopes of the reaction functions in the exclusive regime coincide with the slopes in the non-exclusive regime when $\alpha=1$. When $\alpha>1$, this is not the case. 
Evaluate, for instance, what happens to the marginal productivities of advertising when the competitor increases its advertising with the station that awards it exclusivity (i.e. higher values of $\left.\varphi_{j N P}^{X}\right)$. The sum of the marginal productivities for $i$ across stations changes according to

$$
\frac{\partial^{2} F_{i}}{\partial \varphi_{i N P}^{X} \partial \varphi_{j N P}^{X}}+\frac{\partial^{2} F_{i}}{\partial \varphi_{i N P}^{N X} \partial \varphi_{j N P}^{X}}=-\left(R^{\prime}+V^{\prime}\right) .
$$

It is easy to show that the above expression is strictly positive if

$$
y<\frac{\varphi_{E}^{X} T\left(\varphi_{E}^{X}\right)}{\varphi_{N P}^{N X} T\left(\varphi_{N P}^{N X}\right)}<\frac{2-y}{2 y-1} .
$$

When $G(\varphi)=\varphi^{\eta}$, for instance,

$$
\frac{\varphi_{E}^{X} T\left(\varphi_{E}^{X}\right)}{\varphi_{N P}^{N X} T\left(\varphi_{N P}^{N X}\right)}=1
$$

and the above inequalities are valid since $y<1$ and $\frac{2-y}{2 y-1}>1$. Hence, when the competitor advertises more aggressively on the station that awards it exclusivity, the combined marginal productivities across the two stations rise. This result contradicts the one we obtained in the nonexclusive regime. There, when the competitor increases its advertising level with a station, the combined marginal productivities remain unchanged, thus yielding no change in the aggregate level of advertising of the producer (i.e. $\partial \varphi_{i N P}^{1} / \partial \varphi_{j N P}^{1}+\partial \varphi_{i N P}^{2} / \partial \varphi_{j N P}^{1}=0$ in the non-exclusive regime).

\section{Proof of Proposition 6}

(i) Let

$$
\begin{gathered}
H\left(\varphi_{E}^{X}, \varphi_{N P}^{N X}\right)=T\left(\varphi_{E}^{X}\right)-\frac{(2-y)}{2 t_{s}}\left[1-\frac{(\alpha-1) \varphi_{P}^{X}}{\varphi_{E}^{X}}\right]=0 \\
G\left(\varphi_{E}^{X}, \varphi_{N P}^{N X}\right)=T\left(\varphi_{N P}^{N X}\right)-\frac{\left(2-\frac{1}{y}\right)}{2 t_{s}}=0,
\end{gathered}
$$

where $y \equiv \frac{\left[1-\frac{G\left(\varphi_{E}^{X}\right)}{2}\right] G\left(\varphi_{N P}^{N X}\right)}{\left[1-\frac{G\left(\varphi_{N P}^{N X}\right)}{2}\right] G\left(\varphi_{E}^{X}\right)}$. 
The stability of system (A.15) requires that $H_{\varphi_{E}^{X}}, G_{\varphi_{N P}^{N X}}<0$ and $D \equiv\left\lfloor H_{\varphi_{E}^{X}} G_{\varphi_{N P}^{N X}}-H_{\varphi_{N P}^{N X}} G_{\varphi_{E}^{X}}\right\rfloor>0$. Also notice that

$$
\begin{gathered}
H_{\varphi_{N P}^{N X}}=\frac{1}{2 t_{s}}\left[1-\frac{(\alpha-1) \varphi_{P}^{X}}{\varphi_{E}^{X}}\right] \frac{\partial y}{\partial \varphi_{N P}^{N X}}>0 \\
G_{\varphi_{E}^{X}}=-\frac{1}{2 t_{s} y^{2}} \frac{\partial y}{\partial \varphi_{E}^{X}}>0 .
\end{gathered}
$$

Total differentiation of (A.15) yields the following system:

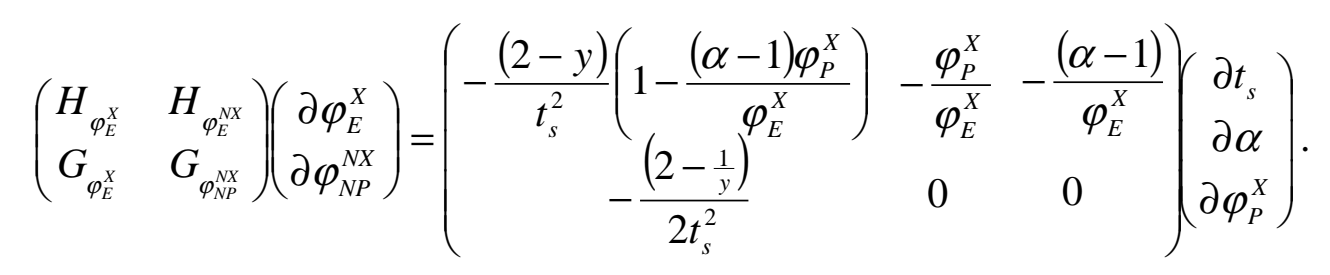

Solving the above system while using the stability condition and (A.16) yields the comparative statics of $\varphi_{E}^{X}$ and $\varphi_{N P}^{N X}$. Using expressions (20) and (21) yields the conclusions related to the price mark-up of each producer and the revenues of each station.

(ii) Notice first that when $\alpha=1$, (19) implies that:

$$
\frac{T\left(\varphi_{N P}^{X}+\alpha \varphi_{P}^{X}\right)}{T\left(\varphi_{N P}^{N X}\right)}=\frac{2-y}{2-\frac{1}{y}}
$$

Assuming that $y<1$ yields that $\varphi_{N P}^{X}+\alpha \varphi_{P}^{X}<\varphi_{N P}^{N X}$ since $T^{\prime}<0$, thus contradicting the assumption that $y<1$. A similar contradiction is reached with the opposite assumption that $y>1$. Hence when $\alpha=1, y=1$ and condition (19) implies that $\varphi_{N P}^{N X}=\varphi_{N P}^{X}+\varphi_{P}^{X}$. When $\alpha>1$ we will first demonstrate that (19) implies that $y<1$. Assume the opposite that $y \geq 1$ then $G\left(\varphi_{N P}^{N X}\right) \geq G\left(\varphi_{N P}^{X}+\alpha \varphi_{P}^{X}\right)$ and $T\left(\varphi_{N P}^{N X}\right) \leq T\left(\varphi_{N P}^{X}+\alpha \varphi_{P}^{X}\right)$. Hence

$$
\frac{T\left(\varphi_{N P}^{X}+\alpha \varphi_{P}^{X}\right)}{T\left(\varphi_{N P}^{N X}\right)} \geq 1
$$

However from (19)

$\frac{T\left(\varphi_{N P}^{X}+\alpha \varphi_{P}^{X}\right)}{T\left(\varphi_{N P}^{N X}\right)}=\frac{(2-y)}{\left(2-\frac{1}{y}\right)} \cdot \frac{\varphi_{N P}^{X}+\varphi_{P}^{X}}{\left(\varphi_{N P}^{X}+\alpha \varphi_{P}^{X}\right)}<1$ by the assumption that $y \geq 1$ and $\alpha>1$.

Hence, a contradiction is reached. As a result, $y<1$ and $\varphi_{N P}^{N X}<\varphi_{E}^{X}=\left(\varphi_{N P}^{X}+\alpha \varphi_{P}^{X}\right)$.

(iii) From (19) 


$$
\begin{gathered}
T\left(\varphi_{E}^{X}\right) \varphi_{E}^{X}=\frac{(2-y)\left(\varphi_{N P}^{X}+\varphi_{P}^{X}\right)}{2 t_{s}} \\
T\left(\varphi_{N P}^{N X}\right) \varphi_{N P}^{N X}=\frac{\left(2-\frac{1}{y}\right)}{2 t_{s}} \varphi_{N P}^{N X}
\end{gathered}
$$

Hence,

$$
\frac{T\left(\varphi_{E}^{X}\right) \varphi_{E}^{X}}{T\left(\varphi_{N P}^{N X}\right) \varphi_{N P}^{N X}}=\frac{(2-y)}{\left(2-\frac{1}{y}\right)} \frac{\left(\varphi_{N P}^{X}+\varphi_{P}^{X}\right)}{\varphi_{N P}^{N X}}
$$

If $T(\varphi) \varphi$ is non-increasing the LHS of (A.17) is less than or equal to one (since $\varphi_{E}^{X}>\varphi_{N P}^{N X}$ from part (ii)). As well, since $y<1$ the ratio $(2-y) /\left(2-\frac{1}{y}\right)$ is strictly bigger than one. Hence (A.17) can hold only if $\varphi_{N P}^{X}+\varphi_{P}^{X}<\varphi_{N P}^{N X}$.

Q.E.D.

\section{Appendix 2}

\section{A Necessary Condition to Support the Exclusive Equilibrium}

We evaluate the profitability of a station that deviates from an exclusive contract. Formally, suppose station 2 offers producer 1 advertising on its primetime slots so that producer 2 is no longer the exclusive advertiser on station 2's primetime.

Recall that in this model, negotiations between stations and producers occur simultaneously with price setting and the decision concerning advertising levels. Therefore, other than variables that pertain to the agreement between station 2 and producer 1, all prices and quantities of advertising remain fixed upon station 2's deviation. In particular, producer 1 continues to advertise $\left(\varphi_{N P}^{X}, \varphi_{P}^{X}\right)$ with station 1 and producer 2 continues to advertise $\varphi_{N P}^{N X}$ with station 1 and $\left(\varphi_{N P}^{X}, \varphi_{P}^{X}\right)$ with station 2 . In contrast, upon the deviation of station 2 , producer 1 and station 2 renegotiate the terms of their agreement, to be designated by $\left(\hat{a}_{N P}, \hat{a}_{P}\right)$, and the producer can simultaneously adjust its level of advertising with this station $\left(\hat{\varphi}_{N P}, \hat{\varphi}_{P}\right)$.

Moreover, since producers' pricing decisions occur at the same time as negotiations, we assume that in the deviation product prices remain at $p^{X}-c$. Deriving the renegotiated advertising rates, given producer 1's demand for advertising with station 2, we can characterize the level of advertising sold by the deviating station to producer 1 as follows: 


$$
T\left(\hat{\varphi}_{N P}+\alpha \hat{\varphi}_{p}\right)=\frac{\hat{\varphi}_{N P}+\hat{\varphi}_{p}}{4 t_{s}\left(\hat{\varphi}_{N P}+\alpha \hat{\varphi}_{p}\right)\left(\frac{1}{2}+\frac{\varphi_{N P}^{N X}-\hat{\varphi}_{N P}-\hat{\varphi}_{P}}{2 t_{s}}\right)}\left(2-\frac{1}{y} \frac{G\left(\varphi_{N P}^{N X}\right)}{G\left(\hat{\varphi}_{N P}+\alpha \hat{\varphi}_{P}\right)}\right) .
$$

We can use (B.1) to compare the intensity of advertising of producer 1 with station 2 before and after the deviation as follows in Proposition B1.

Proposition B1: For $\alpha>1$, the deviation discussed above results in

(i) more effective advertising (i.e. $\hat{\varphi}_{N P}+\alpha \hat{\varphi}_{p}>\varphi_{N P}^{N X}$ )

(ii) less total advertising(i.e. $\left.\hat{\varphi}_{N P}+\hat{\varphi}_{P}<\varphi_{N P}^{N X}\right)$, if $\varphi T(\varphi)$ is non-increasing.

Proof:

(i) Assume the contrary, $\hat{\varphi}_{N P}+\alpha \hat{\varphi}_{p} \leq \varphi_{N P}^{N X}$. This implies $G\left(\varphi_{N P}^{N X}\right) \geq G\left(\hat{\varphi}_{N P}+\alpha \hat{\varphi}_{p}\right)$ and $\varphi_{N P}^{N X}-\hat{\varphi}_{N P}-\hat{\varphi}_{p}>0$, since $\alpha>1$. Therefore,

$$
\frac{\hat{\varphi}_{N P}+\hat{\varphi}_{p}}{4 t_{s}\left(\hat{\varphi}_{N P}+\alpha \hat{\varphi}_{p}\right)\left(\frac{1}{2}+\frac{\left.\varphi_{N P}^{N E}-\hat{\varphi}_{N P}-\hat{\varphi}_{p}\right)}{2 t_{s}}\right)}\left(2-\frac{1}{y} \frac{G\left(\varphi_{N P}^{N E}\right)}{G\left(\hat{\varphi}_{N P}+\alpha \hat{\varphi}_{p}\right)}\right)<\frac{1}{2 t_{s}}\left(2-\frac{1}{y}\right)=T\left(\varphi_{N P}^{N X}\right) .
$$

The above inequality implies that $T\left(\hat{\varphi}_{N P}+\alpha \hat{\varphi}_{P}\right)<T\left(\varphi_{N P}^{N X}\right)$. Since $T$ is decreasing, $\hat{\varphi}_{N P}+\alpha \hat{\varphi}_{p}>\varphi_{N P}^{N X}$, which is a contradiction.

(ii) The result proved in (i) implies $G\left(\varphi_{N P}^{N X}\right)<G\left(\hat{\varphi}_{N P}+\alpha \hat{\varphi}_{p}\right)$. Rearranging (B1), this implies

$$
\hat{\varphi}_{N P}+\hat{\varphi}_{p}<\frac{2\left(\frac{1}{2}+\frac{\varphi_{N P}^{N X}-\hat{\varphi}_{N P}-\hat{\varphi}_{p}}{2 t_{s}}\right)}{T\left(\varphi_{N P}^{N X}\right)}\left(\hat{\varphi}_{N P}+\alpha \hat{\varphi}_{p}\right) T\left(\hat{\varphi}_{N P}+\alpha \hat{\varphi}_{p}\right) .
$$

Now assume the contrary, that $\hat{\varphi}_{N P}+\hat{\varphi}_{P} \geq \varphi_{N P}^{N X}$. This yields

$$
\varphi_{N P}^{N X} T\left(\varphi_{N P}^{N X}\right) \leq\left(\hat{\varphi}_{N P}+\alpha \hat{\varphi}_{p}\right) T\left(\varphi_{N P}^{N X}\right)<\left(\hat{\varphi}_{N P}+\alpha \hat{\varphi}_{p}\right) T\left(\hat{\varphi}_{N P}+\alpha \hat{\varphi}_{p}\right) .
$$

The inequality reflected by outside expressions is a contradiction to the above assumption, as long as $\varphi T(\varphi)$ is non-increasing.

Q.E.D. 
The proposition says that, if allowed to advertise on station 2's primetime when formerly excluded, producer 1 will buy less advertising in total, but will advertise more effectively. Once again, producer 1 finds it advantageous to trade off volume for effectiveness of advertising.

Next we derive a condition for which it is unprofitable for station 2 to deviate from its exclusive contract with producer 2 . The gain from deviation is $\hat{a}_{N P} \hat{\varphi}_{N P}+\hat{a}_{P} \hat{\varphi}_{P}$. It is less than $a_{N P}^{N X} \varphi_{N P}^{N X}$ if and only if

$$
\frac{1}{2}\left(\frac{G\left(\hat{\varphi}_{N P}+\alpha \hat{\varphi}_{p}\right)}{G\left(\varphi_{N P}^{N X}\right)}-1\right)<\left(\frac{\varphi_{N P}^{N X}-\hat{\varphi}_{N P}-\hat{\varphi}_{p}}{2 t_{s}}\right)\left(\frac{1}{y}-\frac{G\left(\hat{\varphi}_{N P}+\alpha \hat{\varphi}_{p}\right)}{G\left(\varphi_{N P}^{N X}\right)}\right) .
$$

Hence, (B2) is a necessary and sufficient condition for the deviation from the exclusive contract to be unprofitable. This condition states that the loss in volume of advertising sold to producer 1 when he is offered space on station 2's primetime is sufficiently large to more than offset the higher prices that this station can command for primetime advertising.

\begin{tabular}{|c|c|c|c|c|c|c|}
\hline \multirow{2}{*}{$\alpha$} & \multicolumn{2}{|c|}{$a_{N P}^{N X} \varphi_{N P}^{N X}$} & \multicolumn{2}{c|}{$\hat{a}_{N P} \hat{\varphi}_{N P}+\hat{a}_{P} \hat{\varphi}_{P}$} & \multicolumn{2}{c|}{$\begin{array}{c}\text { Net Benefit from } \\
\text { Deviation }\end{array}$} \\
\cline { 2 - 7 } & $t_{s}=1$ & $t_{s}=1.25$ & $t_{s}=1$ & $t_{s}=1.25$ & $t_{s}=1$ & $t_{s}=1.25$ \\
\hline 1 & .108 & .120 & .093 & .102 & -.015 & -.018 \\
\hline 1.2 & .123 & .132 & .116 & .122 & -.007 & -.010 \\
\hline 1.4 & .141 & .146 & .136 & .142 & -.005 & -.004 \\
\hline 1.6 & .160 & .161 & .155 & .156 & -.005 & -.005 \\
\hline 1.8 & .181 & .178 & .171 & .170 & -.010 & -.008 \\
\hline 2 & .202 & .195 & .186 & .183 & -.016 & -.012 \\
\hline
\end{tabular}

Table B.1: Incentive for Deviation: Comparative Statics with respect to $\alpha$ and $t_{s}$

$$
\left(\eta=.6 \text { and } \varphi_{P}^{X}=\hat{\varphi}_{P}=.5\right)
$$

Note that while inequality (B.2) is independent of the parameter $t_{p}$ it does depend on the values of $\alpha$ and $t_{s}$. While we are unable to derive the general relationship between the extent of incentives to deviate and the values of those parameters, numerical calculations for the example $G\left(\varphi_{E}\right)=\varphi_{E}^{\eta}$ indicate that for certain values of $\alpha, t_{s}, \eta$, and a fixed level $\varphi_{P}$, the station finds it unprofitable to deviate, thus sustaining exclusivity as an equilibrium. (See Table B.1.) 


\section{Exclusivity Contracts on Non-Primetime}

Using similar notation to that used in the main text, let $\varphi_{P}^{X}$ and $\varphi_{N P}^{X}$ be the levels of advertising of the producer who is awarded an exclusivity contract on non-primetime and let $\varphi_{P}^{N X}$ be the level of advertising of the excluded producer on primetime. Considering once again symmetric equilibria, where each station awards an exclusivity contract to a different producer, we can obtain the following characterization of the effective levels of advertising chosen at the equilibrium:

$$
\begin{aligned}
T\left(\varphi_{N P}^{X}+\alpha \varphi_{P}^{X}\right) & =\frac{(2-y)\left(\varphi_{N P}^{X}+\varphi_{P}^{X}\right)}{2 t_{s}\left(\varphi_{N P}^{X}+\alpha \varphi_{P}^{X}\right)} \\
T\left(\alpha \varphi_{P}^{N X}\right) & =\frac{1}{2 t_{s}}\left(2-\frac{1}{y}\right)
\end{aligned}
$$

where

$$
y \equiv \frac{\left(1-\frac{G\left(\varphi_{N P}^{X}+\alpha \varphi_{P}^{X}\right)}{2}\right) G\left(\alpha \varphi_{P}^{N X}\right)}{\left(1-\frac{G\left(\alpha \varphi_{P}^{N X}\right)}{2}\right) G\left(\varphi_{N P}^{X}+\alpha \varphi_{P}^{X}\right)} .
$$

It is easy to show that $y>1$ and $\alpha \varphi_{P}^{N X}>\left(\varphi_{N P}^{X}+\alpha \varphi_{P}^{X}\right)$. Moreover, if $T\left(\varphi_{E}\right) \varphi_{E}$ is a nonincreasing function then $\varphi_{P}^{N X}<\left(\varphi_{N P}^{X}+\varphi_{P}^{X}\right)$. Hence, with exclusivity contracts awarded for nonprimetime, it is the excluded producer who ends up obtaining an improved outreach probability with the station even though its intensity of advertising declines. It appears that it pays to be excluded in this case.

If the station deviates from the exclusive contracts described above by offering both producers the opportunity to advertise on its non-primetime, the formerly excluded producer would increase its overall intensity of advertising but its outreach probability would decline (opposite effects to those described upon deviation from exclusive agreements on primetime). If the increase in volume is sufficiently large, as is stated in condition (B.2), each station would have an incentive to deviate and an exclusive agreement on non-primetime would not survive as an equilibrium. 
The Yrjö Jahnsson's Working Paper Series in Industrial Economics is funded by The Yrjö Jahnsson Foundation.

Editor of the Working Paper Series: Professor Rune Stenbacka

1. Anthony Dukes \& Esther Gal-Or: Negotiations and Exclusivity Contracts for Advertising 